\title{
Results of the IEA Round Robin on Fast Pyrolysis Bio-oil Production
}

Douglas C. Elliott* Pacific Northwest National Laboratory, Richland, Washington, USA

Dietrich Meier, Thünen Institute of Wood Research, Hamburg, Germany

Anja Oasmaa, VTT Technical Research Center of Finland, Espoo, Finland

Bert van de Beld, BTG Biomass Technology Group BV, Enschede, Netherlands

Anthony V. Bridgwater, Aston University, Birmingham, UK

Magnus Marklund, SP Energy Technology Center, Piteå, Sweden

*author to whom correspondence should be addressed: dougc.elliott@pnnl.gov

\begin{abstract}
An international round robin study of the production of fast pyrolysis bio-oil was undertaken. Fifteen institutions in six countries contributed. Three biomass samples were distributed to the laboratories for processing in fast pyrolysis reactors. Samples of the bio-oil produced were transported to a central analytical laboratory for analysis. The round robin was focused on validating the pyrolysis community understanding of production of fast pyrolysis bio-oil by providing a common feedstock for bio-oil preparation. The round robin included:

- distribution of 3 feedstock samples from a common source to each participating laboratory;

- preparation of fast pyrolysis bio-oil in each laboratory with the 3 feedstocks provided;

- return of the 3 bio-oil products (minimum $500 \mathrm{ml}$ ) with operational description to a central analytical laboratory for bio-oil property determination.

The analyses of interest were: density, viscosity, dissolved water, filterable solids, CHN, S, trace element analysis, ash, total acid number, pyrolytic lignin, and accelerated aging of biooil. In addition, an effort was made to compare the bio-oil components to the products of analytical pyrolysis through GC/MS analysis. The results showed that clear differences can occur in fast pyrolysis bio-oil properties by applying different reactor technologies or configurations. The comparison to analytical pyrolysis method suggested that Py-GC/MS could serve as a rapid screening method for bio-oil composition when produced in fluid-bed reactors. Furthermore, hot vapor filtration generally resulted in the most favorable bio-oil product, with respect to water, solids, viscosity, and total acid number. These results can be helpful in understanding the variation in bio-oil production methods and their effects on biooil product composition.
\end{abstract}

KEYWORDS:

Fast pyrolysis; bio-oil; biomass; 


\section{INTRODUCTION}

Bio-oils from fast pyrolysis of lignocellulosic biomass have been defined as represented in CAS \#1207435-39-9: "Liquid condensate recovered by thermal treatment of lignocellulosic biomass at short hot vapor residence time (typically less than about 5 seconds) typically at between $450-600{ }^{\circ} \mathrm{C}$, at near atmospheric pressure or below, in the absence of oxygen, and using small (typically less than $5 \mathrm{~mm}$ ) dry (typically less than $10 \%$ water) biomass particles" ${ }^{1}$.

A number of engineered systems have been used to effect high heat transfer into the biomass particle and quick quenching of the vapor product, usually after removal of solid byproduct "char", to recover a single phase liquid product.

Bio-oil is a complex mixture of, for the most part, oxygenated hydrocarbon fragments derived from the biopolymer structures. It typically contains $15-30 \%$ water. Common organic components include acetic acid, methanol, aldehydes and ketones, cyclopentenones, furans, alkyl-phenols, alkyl-methoxy-phenols, anhydrosugars, and oligomeric sugars and waterinsoluble lignin-derived compounds. Nitrogen- and sulfur-containing compounds are also sometimes found depending on the biomass source."1

A first set of burner fuel specifications has been accepted for fast pyrolysis bio-oil as ASTM D7544. ${ }^{2}$ The first standard method, ASTM D7579, was obtained for determination of the insoluble solids content. The ASTM method includes the validation results of a 2laboratory test over 10 successive days as represented by the Repeatability measurement.

Bio-oils have many important differences from mineral oils. ${ }^{3}$ The standard analyses have been systematically tested for bio-oils ${ }^{4-8}$ and modifications as well as new methods have been suggested when needed.

The first IEA (International Energy Agency) Bioenergy Round Robin was carried out by Elliott, McKinley and Overend. ${ }^{9}$ It was found out that xylene distillation EN 95, which is used for mineral oils, cannot be used for the determination of water content of fast pyrolysis bio-oils because bio-oils contain a significant amount of volatile water-soluble compounds that end up being counted as part of the water fraction by this method. Karl-Fischer titration was recommended as a suitable method for fast pyrolysis bio-oils.

Two separate Round Robin tests were initiated in 1997: one within EU PyNe (Pyrolysis Network) ${ }^{10}$ and the other within IEA PYRA (Pyrolysis Activity). ${ }^{10}$ From both of them it was concluded that the precision of carbon, hydrogen, density, and water by KarlFischer titration was good. High variations were obtained for nitrogen, viscosity, $\mathrm{pH}$, and solids. The conclusion was also that clear instructions for analyses are needed.

In 2001 a Round Robin ${ }^{11}$ was organized within the IEA-EU PyNe (Pyrolysis Network) cooperation. Analyses were carried out by 12 laboratories for four different fast pyrolysis biooils (originating from pine, spruce, hardwood mix, and bark) produced by different largescale pyrolysis processes. Water, solids content, $\mathrm{pH}$, viscosity, stability test, and CHN determinations were included. In general, the accuracy of physical analyses, except the stability test, was good.

The Round Robin conducted in $2012^{12-13}$ was focused on testing viscosity and the stability method as an accelerated aging test and subsequent long term storage stability testing. It was concluded that kinematic viscosity is more accurate than dynamic viscosity.

This paper is focused on validating the production of consistent quality bio-oil at the collection of R\&D laboratories involved in development of this new product. The importance in understanding the variation in bio-oil products increases as new researchers enter the field as has been experienced over the past 5 years. 


\section{MATERIALS AND METHODS}

The research was carried out within the IEA Bioenergy Agreement Pyrolysis Task 34. This paper summarizes results from the tests performed in the participating laboratories.

Fifteen institutions from the six participating countries in Task 34 agreed to contribute to this Round Robin and each was supplied with samples of three biomass feedstocks for fast pyrolysis processing. The participants included:

$\underline{\mathrm{USA}}$

- Pacific Northwest National Laboratory, USA - Daniel T. Howe and Daniel M. Santosa

- National Renewable Energy Laboratory, USA - Kristiina Iisa

- Michigan State University, USA - Chris Saffron/Rachael Sak

- Iowa State University, USA - Ryan G. Smith

- University of Maine, USA - William DeSisto

$\underline{\mathrm{UK}}$

- Aston University, UK - Daniel Nowakowski

- Future Blends, Ltd., UK - Zhiheng Wu

- University of Leeds, UK - Paul Williams

$\underline{\text { Germany }}$

- Fraunhofer UMSICHT, Germany - Tim Schulzke

- Karlsruhe Institute of Technology, Germany - Axel Funke

- Thünen Institute of Wood Research, Germany - Dietrich Meier

The Netherlands

- University of Groningen, Netherlands - Erik Heeres

- ECN - Paul deWild

Finland

- VTT, Technical Research Centre of Finland, Finland - Ville Paasikallio

$\underline{\text { Sweden }}$

- SP-Energy Technology Center, Sweden - Ann-Christine Johansson

Three biomass feedstocks were provided and distributed by the Idaho National Laboratory (Idaho Falls, Idaho, USA) as funded by the Bioenergy Technologies Office of the U.S. Department of Energy. They were:

- Hybrid Poplar wood from Morrow county, Oregon

- Wheat straw from Jefferson county, Idaho, and

- Blended feedstock (hybrid poplar (70\%), wheat straw (15\%) and forest thinnings $(15 \%)$. The forest thinnings consisted of a mixture of hemlock and Douglas fir. All samples were ground to fine particle size, pelletized and then reground in a hammer mill using a $1.3 \mathrm{~mm}$ screen to produce a fine meal. The nominal particle size was approximately $1 \mathrm{~mm}$, with the width of largest particles approaching $2 \mathrm{~mm}$. The maximum 
particle thickness appeared to be approximately $1 \mathrm{~mm}$. Some instructions for the handling of the biomass feedstocks and the bio-oil products were also provided.

\section{Analytical methods.}

Density: Density was measured at $20{ }^{\circ} \mathrm{C}$ using a special pycnometer $(10 \mathrm{ml})$ with separate side capillary.

Viscosity: Kinematic viscosity was determined with an automatic capillary viscometer model AVS 350 and the corresponding water baths CT 1650 from Schott (Mainz, Germany). Determination was according to DIN 51562 part 1 and 2. Viscometers were of the Ubbelohde type with capillary diameters of 1.13 and $2.01 \mathrm{~mm}$. Viscosities were measured at 20 and 50 ${ }^{\circ} \mathrm{C}$.

Ageing: $40 \mathrm{~mL}$ of bio-oil were placed in a $100 \mathrm{~mL}$ glass bottle from Scott equipped with a screw cap. The bottle was closed and put into a preheated oven at $80{ }^{\circ} \mathrm{C}$ for 24 hours.

Water content: The water content was determined by Karl-Fischer titration using the Titroline alpha apparatus from Schott-Geräte GmbH (Mainz, Gemany). The titrant was Hydranal Composite 2 and the solvent "methanol rapid" (a special reagent for accelerated volumetric one-component KF titration) both from Fluka/Sigma Aldrich, Germany. The endpoint of the titration was potentiometrically determined by dead-stop-indication. All determinations were at least made in duplicate.

Total acid number (TAN): TAN was determined by manual titration. Ca. $3 \mathrm{~g}$ bio-oil was used and titrated with a solution of $\mathrm{KOH}$ in ethanol $(0.5 \mathrm{~mol} / \mathrm{L})$. A combination electrode model BlueLine $12 \mathrm{pH}$ from SI Analytic was used.

Ash: Ash content was determined according to TAPPI standard (T211 om-02). Approximately 5-6 g of bio-oil were used for ash determination at $775{ }^{\circ} \mathrm{C}$

Elemental composition: Carbon, hydrogen and nitrogen were determined with model Vario EL from ELEMENTAR, Hanau, Germany. Oxygen was calculated by difference as follows: $\mathrm{O} \%=100-[\mathrm{C} \%+\mathrm{H} \%+\mathrm{N} \%]$.

Pyrolytic Lignin (PL): Pyrolytic lignin was determined following the method of Scholze and Meier. ${ }^{14} \mathrm{Ca} .1 .0-1.4 \mathrm{~g}$ of bio-oil were added to kitchen mixer filled with $1 \mathrm{~L}$ distilled water at room temperature and vigorously stirred. The precipitate (PL) was filtered over a Büchner funnel (filter paper MN 615 (Machery \& Nagel, Germany), washed several times with water, dried under vacuum at $40{ }^{\circ} \mathrm{C}$ resulting in a powder-like brownish product, and finally weighed.

Solids: Solids were determined according to ASTM D-7579-09. Bio-oil samples was dissolved on a 1:1 mixture of methanol and dichloromethane (DCM) and filtered.

Ash composition: Ash composition was determined by ICP/OES (Inductively Coupled Plasma-Optical Emission Spectrometry). Measurements were performed on a Thermo iCAP 6300 Duo spectrometer. Ca. $350 \mathrm{mg}$ bio-oil were digested in $2.5 \mathrm{~mL}$ nitric acid (65\%).

Gel permeation chromatography (GPC): Mean molecular weight was determined from biooils and the pyrolytic lignins. GPC was performed on an Agilent 1100 series equipped with PolarGel-L Guard $50 \mathrm{~mm} \times 7.5 \mathrm{~mm}$ and 2x Varian PolarGel-L; each $300 \mathrm{~mm}$, I.D. $7.5 \mathrm{~mm}$, 
using dimethyl sulfoxide with $0.1 \mathrm{wt} \% \mathrm{LiBr}$ as eluent. Also, $100 \mu \mathrm{L}$ of solutions containing 2 $\mathrm{mg} \mathrm{mL}-1$ of analyte were injected. The system was calibrated using polyethylene glycol (PEG) standards (194 to 21,030 g/mol). A UV detector at $254 \mathrm{~nm}$ was used to monitor the sample signals.

Gas chromatography/mass spectrometry (GC/MS): Compositions of bio-oils were analyzed using a HP 6890 gas chromatograph from Agilent. Around $60 \mathrm{mg}$ of the sample was dissolved in $1 \mathrm{~mL}$ acetone, which contained a known amount of fluoranthene as internal standard (IS) for quantification. Injection split ratio was 1:15 and injection volume was 1 microliter. Separation was carried out on a $60 \mathrm{~m} 0.25 \mathrm{~mm}$ VF-1701ms (Agilent) fused-silica column. The oven was hold constant at $45^{\circ} \mathrm{C}$ for 4 min and then heated with $3{ }^{\circ} \mathrm{C} / \mathrm{min}$ to $280{ }^{\circ} \mathrm{C}$ and held for $20 \mathrm{~min}$. Helium was used as carrier gas with a constant flow of $2 \mathrm{~mL} / \mathrm{min}$. Parallel MS/FID detection (mass spectrometry/flame ionization detector) was used for improved qualification and quantification. Ionization energy was $70 \mathrm{eV}$. Electron impact (EI) mass spectra were obtained on a HP 5972 MS system. Fluoranthene was used as internal standard (IS) for quantification with the FID. Total ion chromatograms (TIC) were analyzed with Mass Finder 4 by comparison of both mass spectra from home-developed MS-library and commercial NIST library. Most of the compounds were quantified by use of standards. For those which were not quantifiable by a suitable standard, and after matching with NIST spectral library, a response factor was assigned based on standards with similar chemical structure.

Analytical pyrolysis: Prior to pyrolysis, the biomass samples were milled in a cryo-mill. Approximately $100 \mu \mathrm{g}$ of fine-milled sample was weighed in a stainless steel pyrolysis cup (Fontier Lab Ltd., Japan) placed into the autosampler of a double-shot Py-2020iD 2020 microfurnace pyrolyzer (Frontier Laboratories Ltd.) mounted on an Agilent 6890 GC system. The GC is equipped with a VF-1701 (Agilent) fused-silica capillary column $(60 \mathrm{~m} 0.25 \mathrm{~mm}$ i.d., $0.25 \mu \mathrm{m}$ film thickness) and an Agilent 5973 mass selective detector (EI at $70 \mathrm{eV}$, ion source temp $280{ }^{\circ} \mathrm{C}$ ). Pyrolysis was carried out at $500^{\circ} \mathrm{C}$. For separation with $\mathrm{GC}$, the oven temperature was held at $45{ }^{\circ} \mathrm{C}(4 \mathrm{~min})$ and raised to 255 at $3{ }^{\circ} \mathrm{C}$ min-1 (70 min) using He as carrier gas $(1 \mathrm{~mL} / \mathrm{min})$. The compounds were identified using Mass Finder 4 by comparing their mass spectra in NIST and home-developed libraries.

\section{RESULTS AND DISCUSSION}

\section{Feedstock analysis, feedback and pyrolysis conditions}

The three biomass samples included poplar wood, wheat straw, and a blended feed. The feedstock analyses are in Table 1.

Table 1. Analysis (dry basis) of the three biomass feedstocks distributed in the Round Robin

\begin{tabular}{lccc}
\hline & Poplar wood & Wheat straw & Blend \\
\hline Volatiles, \% & 84.9 & 72.4 & 76.8 \\
Ash, \% & 0.9 & 12.8 & 5.0 \\
Fixed C, \% & 14.2 & 14.7 & 15.1 \\
Carbon, wt\% & 49.9 & 43.8 & 49.0 \\
Hydrogen, wt\% & 5.8 & 5.3 & 5.8 \\
Nitrogen, wt\% & 0.2 & 0.6 & 0.3 \\
\hline
\end{tabular}


Although the three feedstocks were originally distributed to 20 laboratories, the fast pyrolysis tests were only successfully completed in the 16 reported here. (One institution had 2 laboratories to perform the tests with two different reactor types). The 16 laboratories were able to provide representative bio-oil samples from 2 or 3 of the feedstocks.

The wheat straw has a noticeably high ash content. It is somewhat higher than is typically reported in the literature. With such a feedstock the fast pyrolysis products are affected in that there is typically a reduced bio-oil yield ${ }^{15-16}$ with higher water and gas production. The bio-oil samples produced from the wheat straw feedstock consisted of two phases for all laboratories. This type of phase separation, into a more aqueous lighter phase and a less aqueous heavy phase is often seen when processing agricultural residue feedstocks. It is usually attributed to the higher mineral content in the biomass which catalyzes reactions leading to more water and char formation. The higher yield of water leads to the phase separation which can be spontaneously generated by water addition to bio-oil. ${ }^{15}$ The poplar bio-oils were the most consistently produced product and were received from all participants. Some participants did not provide bio-oil samples from either the wheat straw or the blended feedstock (see Table 2).

Table 2. Bio-oil samples received from the participants

\begin{tabular}{cccc}
\hline laboratory & poplar & wheat straw & blend \\
\hline 1 & $\mathrm{x}$ & $\mathrm{x}$ & $\mathrm{x}$ \\
2 & $\mathrm{x}$ & $\mathrm{x}$ & $\mathrm{x}$ \\
3 & $\mathrm{x}$ & $\mathrm{x}$ & $\mathrm{x}$ \\
4 & $\mathrm{x}$ & $\mathrm{x}$ & $\mathrm{x}$ \\
5 & $\mathrm{x}$ & $\mathrm{x}$ & $\mathrm{x}$ \\
6 & $\mathrm{x}$ & $\mathrm{x}$ & $\mathrm{x}$ \\
7 & $\mathrm{x}$ & $\mathrm{x}$ & $\mathrm{x}$ \\
8 & $\mathrm{x}$ & $\mathrm{x}$ & $\mathrm{x}$ \\
9 & $\mathrm{x}$ & $\mathrm{x}$ & $\mathrm{x}$ \\
10 & $\mathrm{x}$ & $\mathrm{x}$ & \\
11 & $\mathrm{x}$ & & $\mathrm{x}$ \\
12 & $\mathrm{x}$ & $\mathrm{x}$ & $\mathrm{x}$ \\
13 & $\mathrm{x}$ & $\mathrm{x}$ & $\mathrm{x}$ \\
14 & $\mathrm{x}$ & $\mathrm{x}$ & $\mathrm{x}$ \\
15 & $\mathrm{x}$ & $\mathrm{x}$ & $\mathrm{x}$ \\
16 & $\mathrm{x}$ & & $\mathrm{x}$ \\
\hline
\end{tabular}

Table 3. Pyrolysis reactor systems and operating conditions as provided by the participants

\begin{tabular}{cccccc}
\hline $\begin{array}{l}\text { lab. } \\
\text { no. }\end{array}$ & reactor type & $\begin{array}{c}\text { operating } \\
\text { temperature* } \\
{\left[{ }^{\circ} \mathrm{C}\right]}\end{array}$ & $\begin{array}{c}\text { time at } \\
\text { temperature*** } \\
{[\mathrm{s}]}\end{array}$ & $\begin{array}{c}\text { condensation } \\
\text { temperature } \\
{\left[{ }^{\circ} \mathrm{C}\right]}\end{array}$ & $\begin{array}{c}\text { feed rate } \\
{[\mathrm{kg} / \mathrm{h}]}\end{array}$ \\
\hline 1 & bubbling fluid bed & 475 & $<2$ & -5 & $0.18-0.39$ \\
4 & bubbling fluid bed & $480-500$ & & 22 & $0.4-1.7$ \\
5 & bubbling fluid bed & $480-500$ & & 22 & 1.0 \\
9 & bubbling fluid bed & 480 & 0.8 & 22 & 0.8 \\
13 & bubbling fluid bed & 525 & 1.5 & 15 & 0.85
\end{tabular}




\begin{tabular}{|c|c|c|c|c|c|}
\hline 15 & bubbling fluid bed & 500 & 1 & 20 & 0.5 \\
\hline 16 & bubbling fluid bed & 500 & ND & 20 & 8 \\
\hline 2 & $\begin{array}{l}\text { bubbling fluid bed } \\
\text { w/HVF }\end{array}$ & 500 & $1.2+10.8$ & 1 & $0.09-0.12$ \\
\hline 12 & $\begin{array}{l}\text { bubbling fluid bed } \\
w / H V F\end{array}$ & 500 & $0.9+1.0$ & -78 & 0.42 \\
\hline 10 & $\begin{array}{l}\text { entrained flow } \\
w / H V F\end{array}$ & 530 & $2-3$ & -30 & $2-5$ \\
\hline 6 & auger & $483-500$ & $1.1-2.2$ & -5 & $0.24-0.86$ \\
\hline 7 & twin-screw & 500 & 15 for solids & 30 & 10 \\
\hline 8 & screw kiln & 550 & 40 for solids & 0 & 0.24 \\
\hline 14 & screw conveyor & 400 & & -7 & $0.68-0.36$ \\
\hline 3 & ablative plate & 542 wall & & 2 & 10 \\
\hline 11 & ablative cyclone & 750 wall & & 18 to 27 & 20 \\
\hline
\end{tabular}

$w / H V F$ : with hot vapor filtration; $\mathrm{ND}=$ Not Determined. $*$ the control point in the reactor is not exactly known; **vapor residence time in the hot zone

In the following discussion the four categories "BFB" (bubbling fluid bed), "BFB/EF-HVF" (bubbling fluid bed/entrained flow-hot vapor filtration), "screw", and "ablative" will be used according to the subdivisions in Table 3.

The bio-oil products were all received and analyzed at the Thünen Institute of Wood Research in Hamburg, Germany. The results of these analyses are presented and discussed below.

\section{Water content}

Water content of bio-oil is a crucial quality criterion and its importance has been discussed in many papers. ${ }^{17-23}$ It is a sum of biomass moisture and so-called pyrolysis/reaction water. Inevitably, reaction water is formed mainly due to cleavage of glucosidic bonds of cellulose and hemicelluloses. On the other hand, feedstock properties (ash content) and pyrolysis conditions (temperature, hot vapor residence time, char particles) are responsible for secondary cracking reaction leading to water formation. The influence of the feedstock can be seen in Figure 1Error! Reference source not found.

There is a general trend of a higher water content obtained from pyrolysis of the blended feedstock which has an ash content of $5 \%$ (see Table 1). The water content in poplar oils covers a very wide range from 9.4 to 51.4. Typically, the water content of a bio-oil made from hardwood is in the range of $25 \%$. Hence, the extreme values can only be explained through different reactor configurations, abnormal condenser systems, long residence time of hot vapors, poor mass balance, or phase separation. 


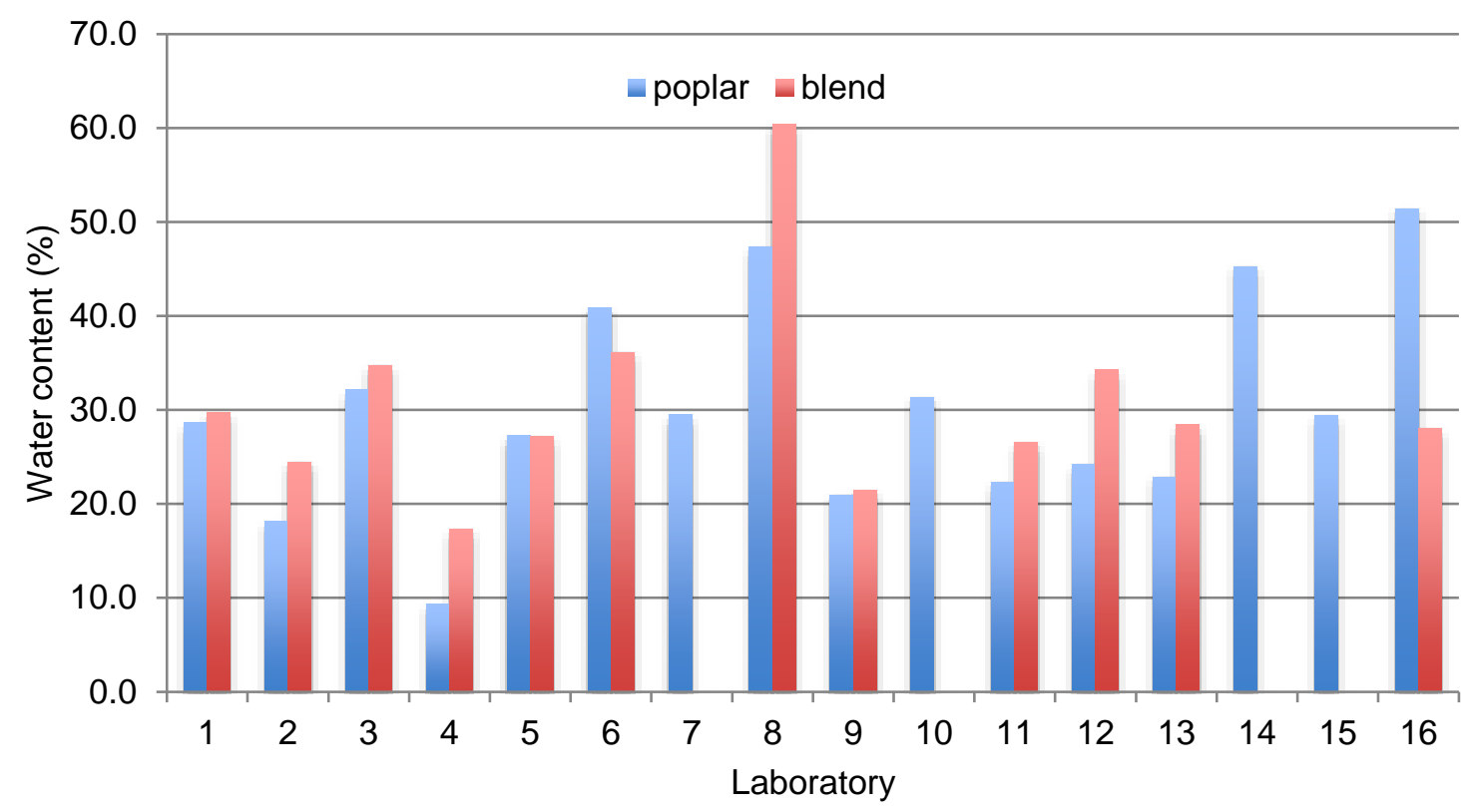

Figure 1. Water contents (wt\%) of bio-oils from poplar and blended feedstock

\section{Density}

Density distribution is presented in Error! Reference source not found.. The densities of the poplar bio-oil samples were fairly consistent throughout, with the exception of \#8 and \#14, whose products appear to be not representative of fast pyrolysis bio-oil. Both of these laboratories are operating screw reactors. The density of poplar bio-oils varies from 1.12 to $1.21 \mathrm{~kg} / \mathrm{dm}^{3}$. Because of the phase separation, the densities of wheat straw bio-oil were difficult to measure in many cases and varied from $1.03-1.13 \mathrm{~kg} / \mathrm{dm}^{3}$ for those recorded. The blended feedstock samples were more consistently measured and varied from 1.12-1.19 $\mathrm{kg} / \mathrm{dm}^{3}$.

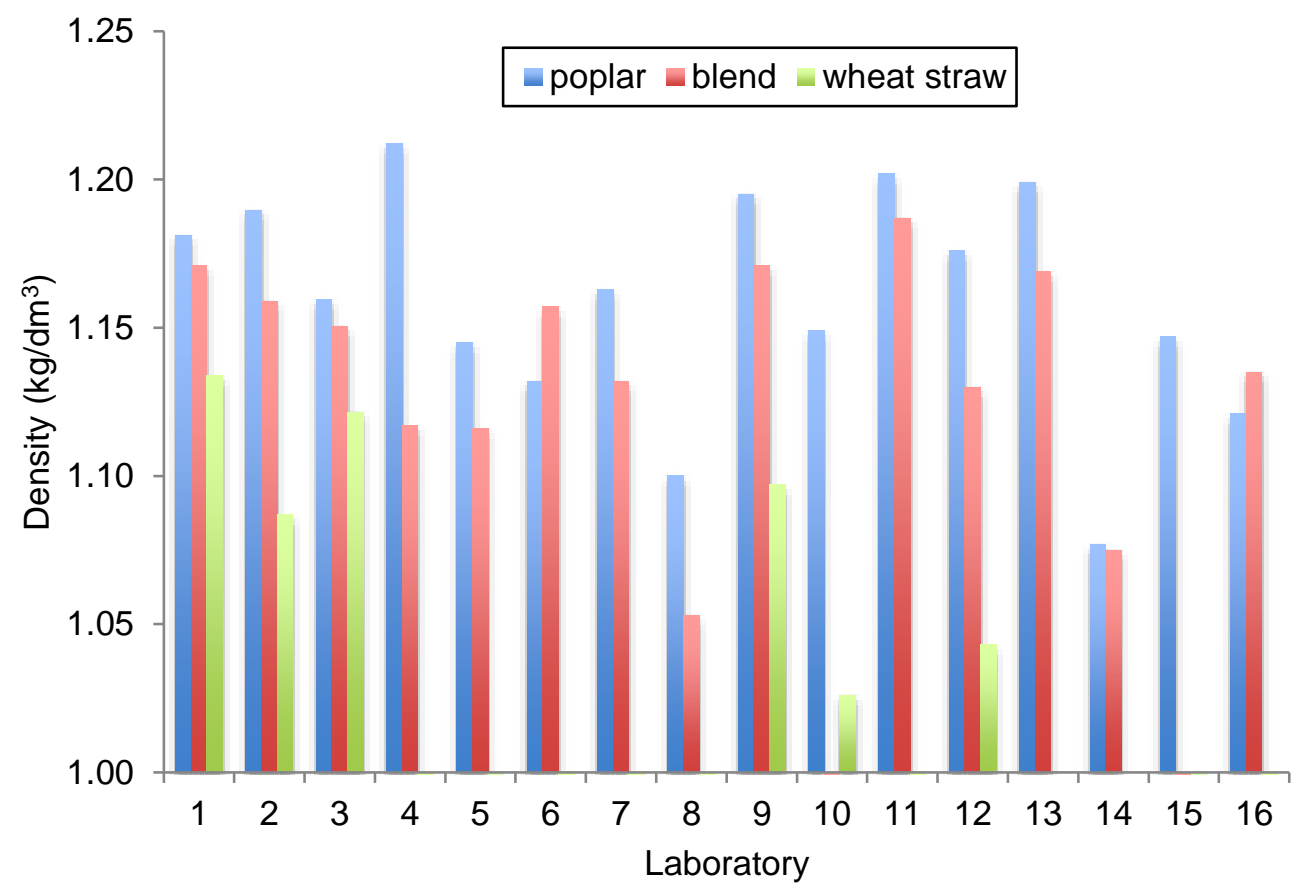


Figure 2. Density distribution of bio-oils from poplar, blend and wheat straw

The density is a function of water content and the variation in water contents is seen in Figure 1. Error! Reference source not found. illustrates this correlation and shows that screw reactors produce bio-oils with a higher water content and, consequently, of lower density. All other technologies, with one exception (\#16) produce oils with reasonable water and density values.

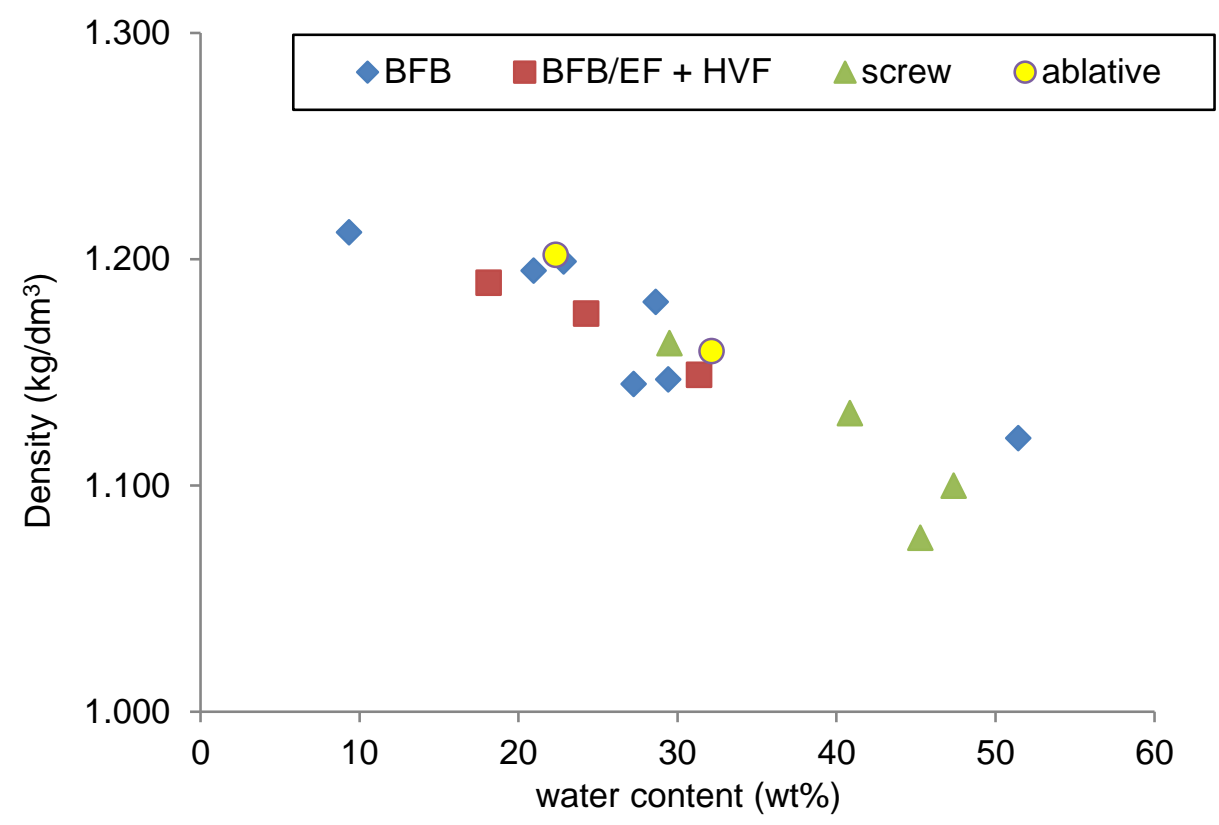

Figure 3. Density/water correlation vs. technology

\section{Viscosity}

In contrast to the relatively even distribution of densities, viscosities show an inconsistent pattern ranging from 6 to $140 \mathrm{cSt}$ (Figure 4).

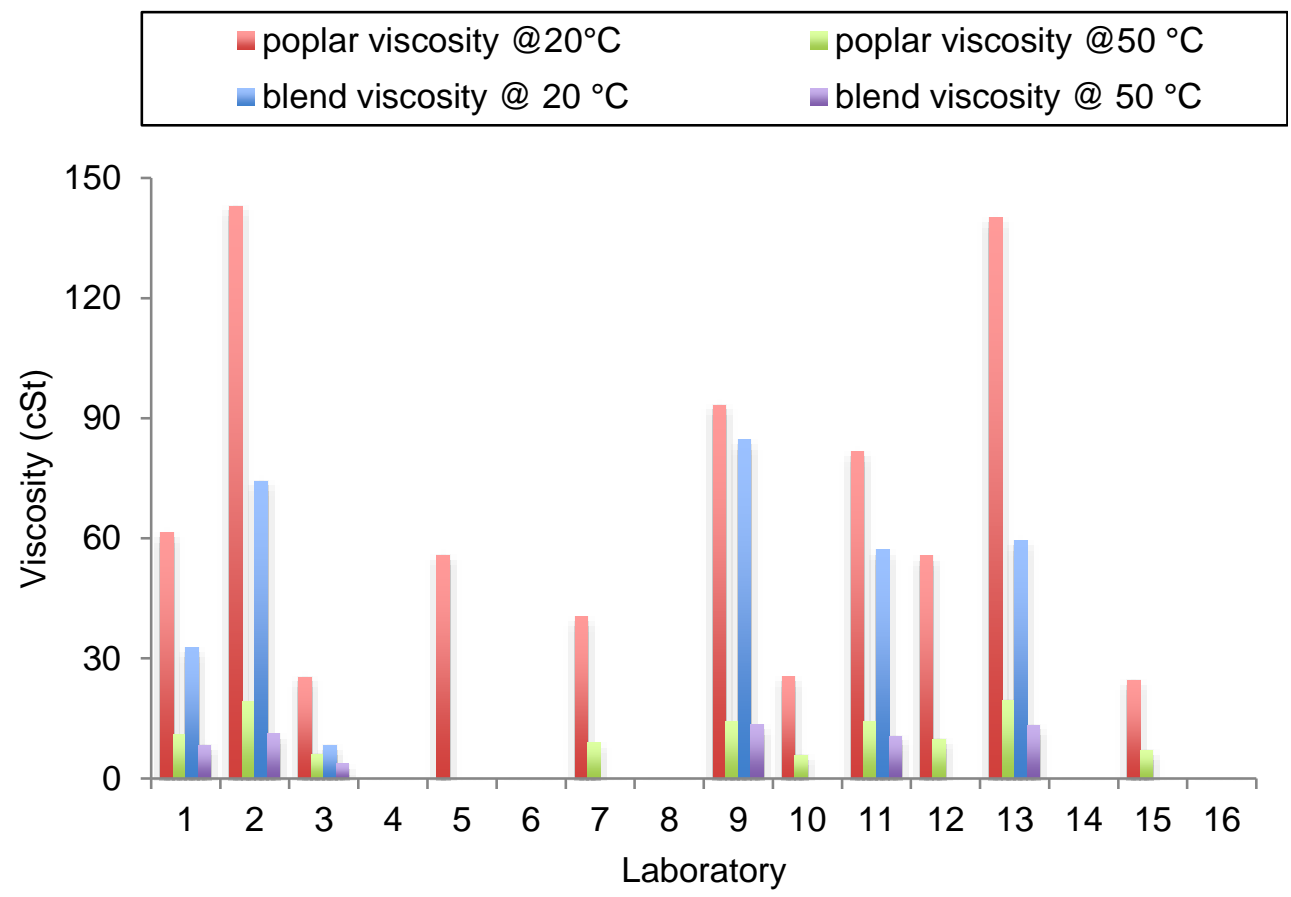


Figure 4. Viscosity distribution of poplar bio-oils

Moisture and viscosity of the bio-oil samples appear to be related, not unexpectedly, in an inverse relationship as also described earlier. ${ }^{5-8}$ The bio-oils from \#4 are distinctly different with extraordinarily low moisture contents that could not be measured with the Ubbelohde viscometer. Oils from \#6, \#8, \#14, and \#16 had water contents $>35 \%$ which is not typical for fast pyrolysis oils and hence are not considered in the viscosity distribution. However, they fit into the correlation curves of Figure 5 and Figure 6. Clearly, the amount of water embedded in bio-oil has an easily discerned effect in that the higher amount of water decreases the viscosity, at both $20^{\circ} \mathrm{C}$ and $50{ }^{\circ} \mathrm{C}$.

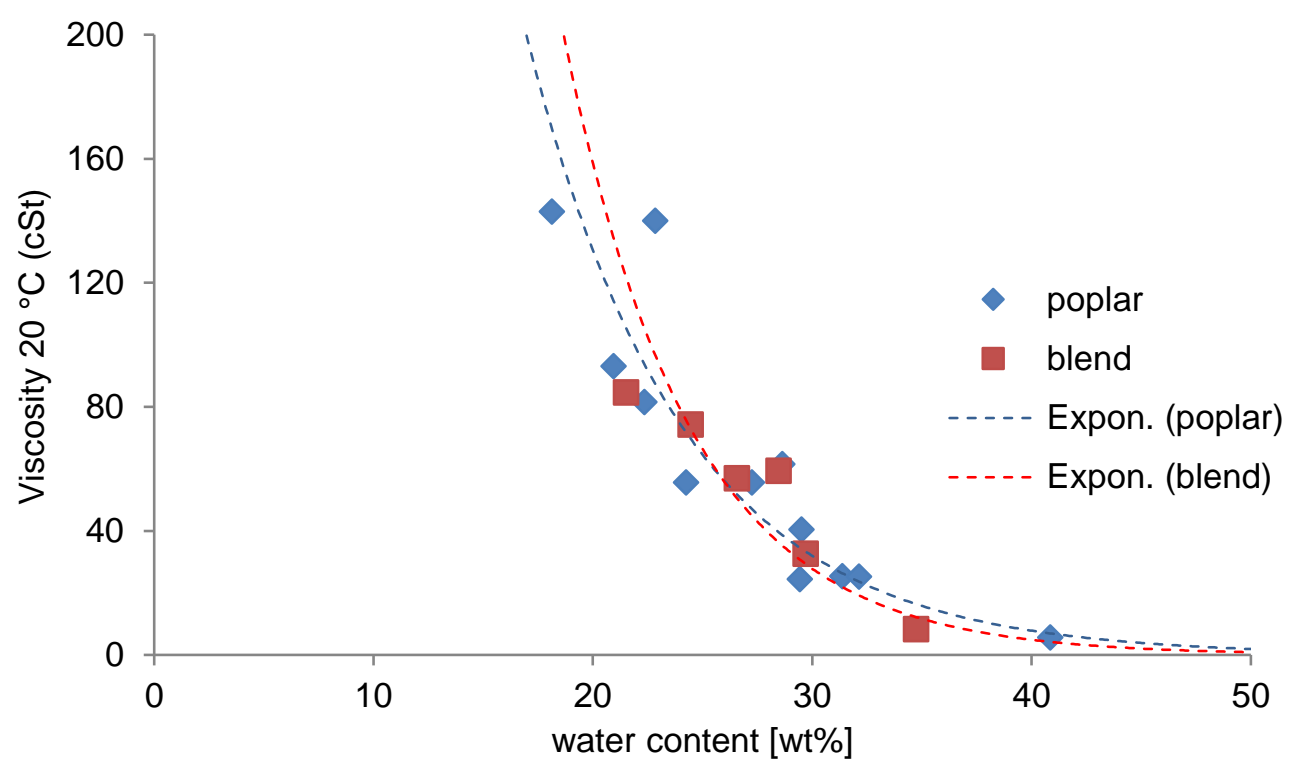

Figure 5. Water/viscosity @ $20{ }^{\circ} \mathrm{C}$ correlation vs. poplar and blend

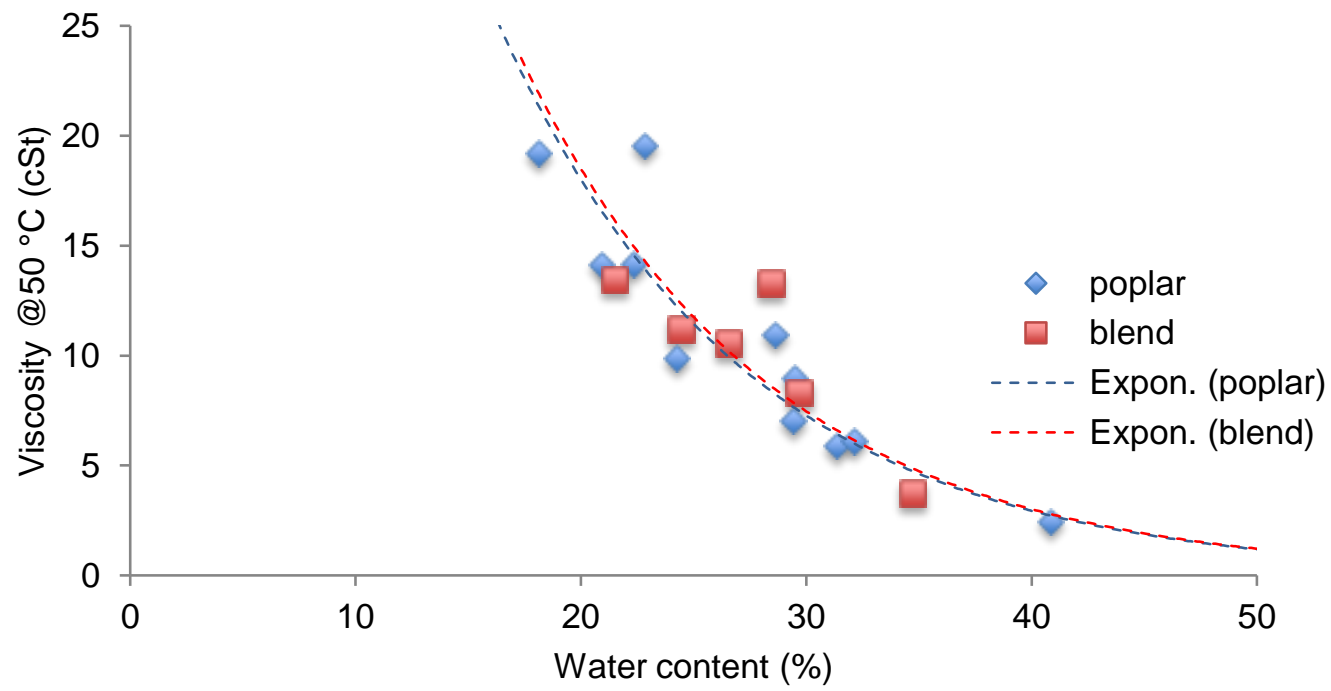

Figure 6. Water/viscosity @ $50{ }^{\circ} \mathrm{C}$ correlation vs. poplar and blend

The ratio of viscosity (viscosity $20^{\circ} \mathrm{C} /$ viscosity $50^{\circ} \mathrm{C}$ ) at the two temperatures also changes over the range of dissolved water as shown in Figure 7 and gives a linear negative 
correlation with a degree of determination of 0.86 . It means that the temperature dependency of the fast pyrolysis bio-oil viscosity is also a function of the water content.

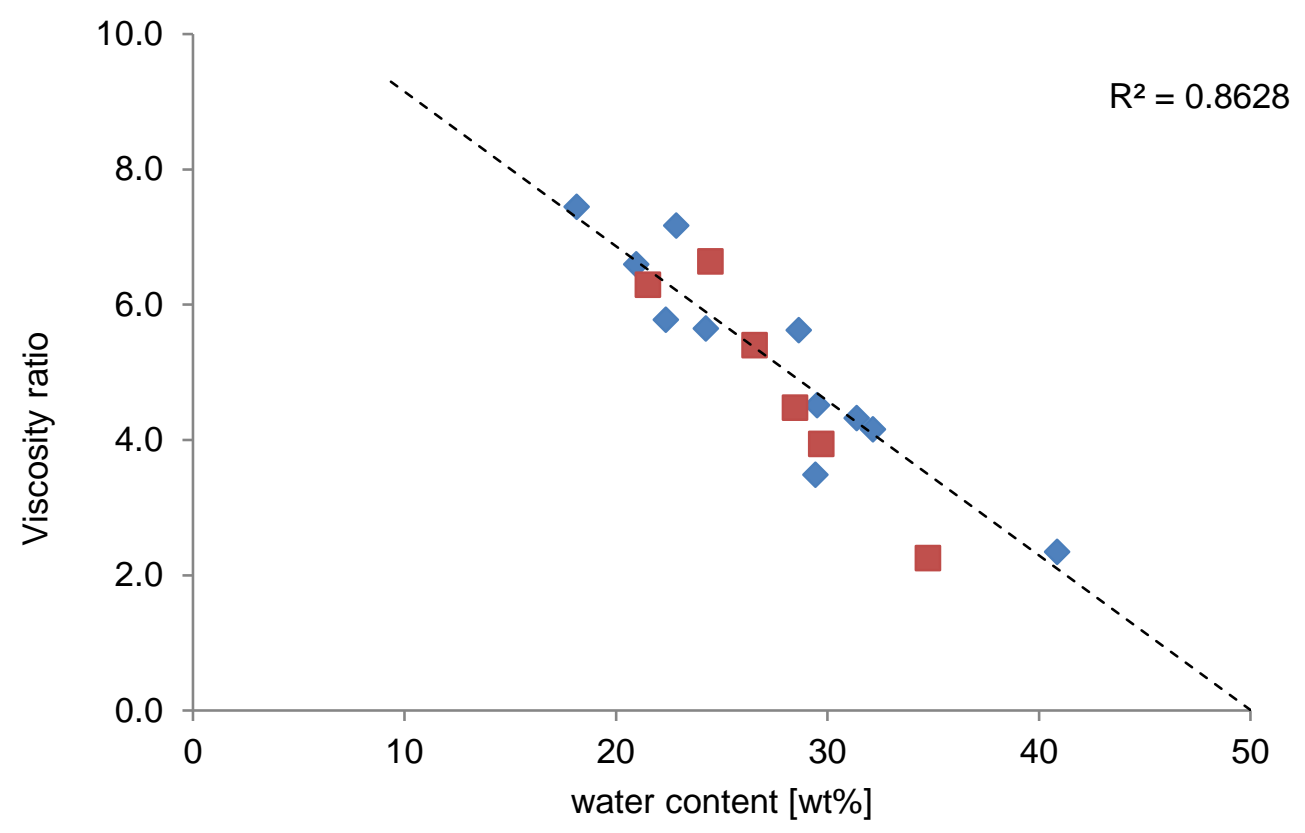

Figure 7 . Viscosity ratio vs. water content ratio=viscosity @20 $\mathrm{C} /$ viscosity @ 50 $\mathrm{C}$

\section{Total acid number (TAN)}

Total acid number is a crucial parameter in biofuels as it determines the tendency for corrosion. Several attempts are described in the literature to decrease TAN ${ }^{24-27}$. The TAN distribution is illustrated in Figure 8 and the technology related graph is presented in Figure 9. It is obvious that lab \#3 (ablative reactor) produced an oil with the highest TAN and that also screw reactors exhibit higher TANs combined with larger water contents. It might be caused by longer residence times enabling more severe cracking towards acids.

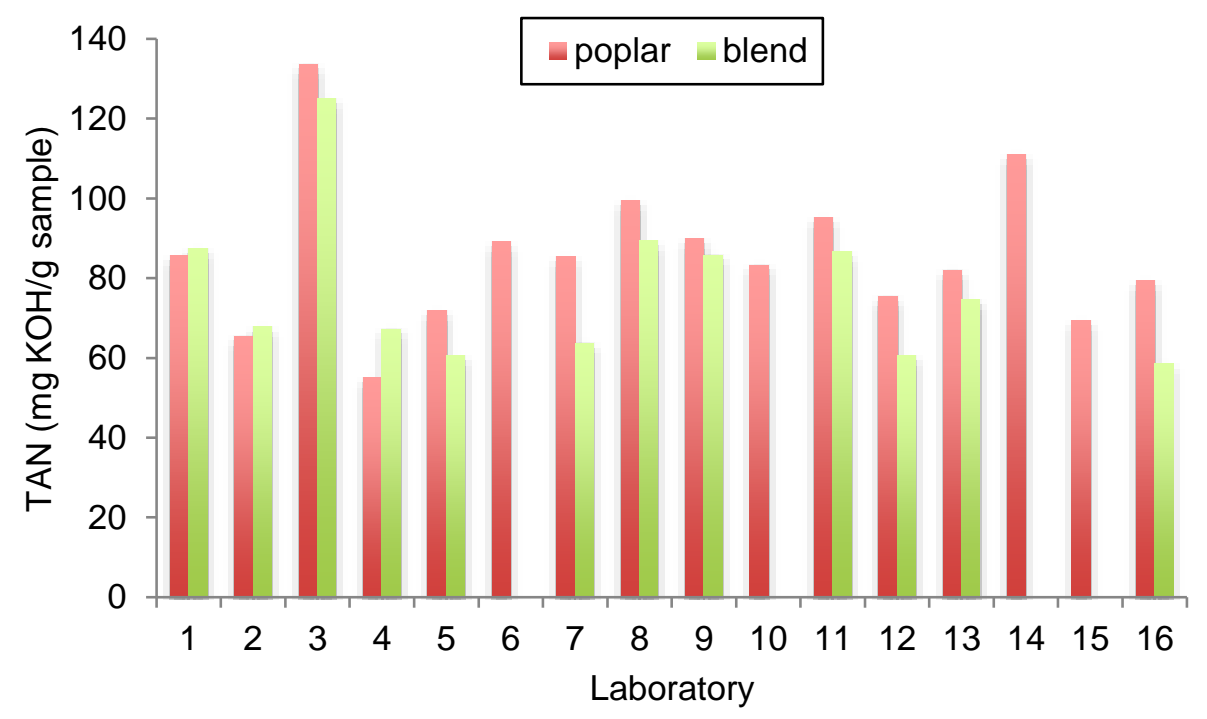

Figure 8. Distribution of total acid number of bio-oils from poplar and blend 


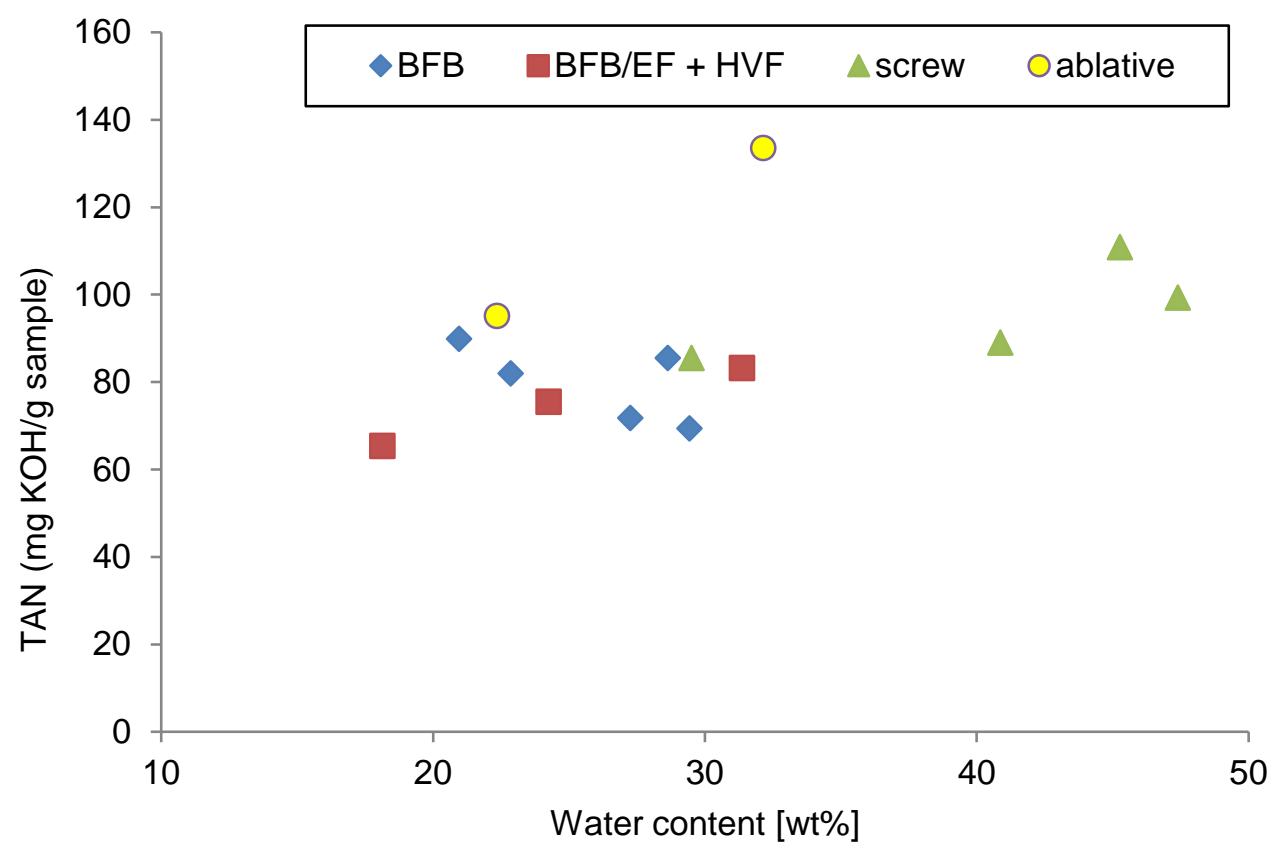

Figure 9. TAN/water correlation vs. technologies

\section{Elemental analysis}

Figure 10 shows the distribution of carbon, hydrogen and nitrogen in poplar bio-oils. The carbon content ranges from 29.4 to $56.3 \mathrm{wt} \%$ on wet basis (w.b.) and from 55.9 to $62.0 \mathrm{wt} \%$ on dry basis (d.b.). The hydrogen contents on d.b. ranges from 6.15 to $7.69 \mathrm{wt} \%$. The lower range is dominated by oils from screw reactors (\#6, \#8, and \#14). Nitrogen values ranged from 0.2 to $0.28 \mathrm{wt} \%$ on d.b. 


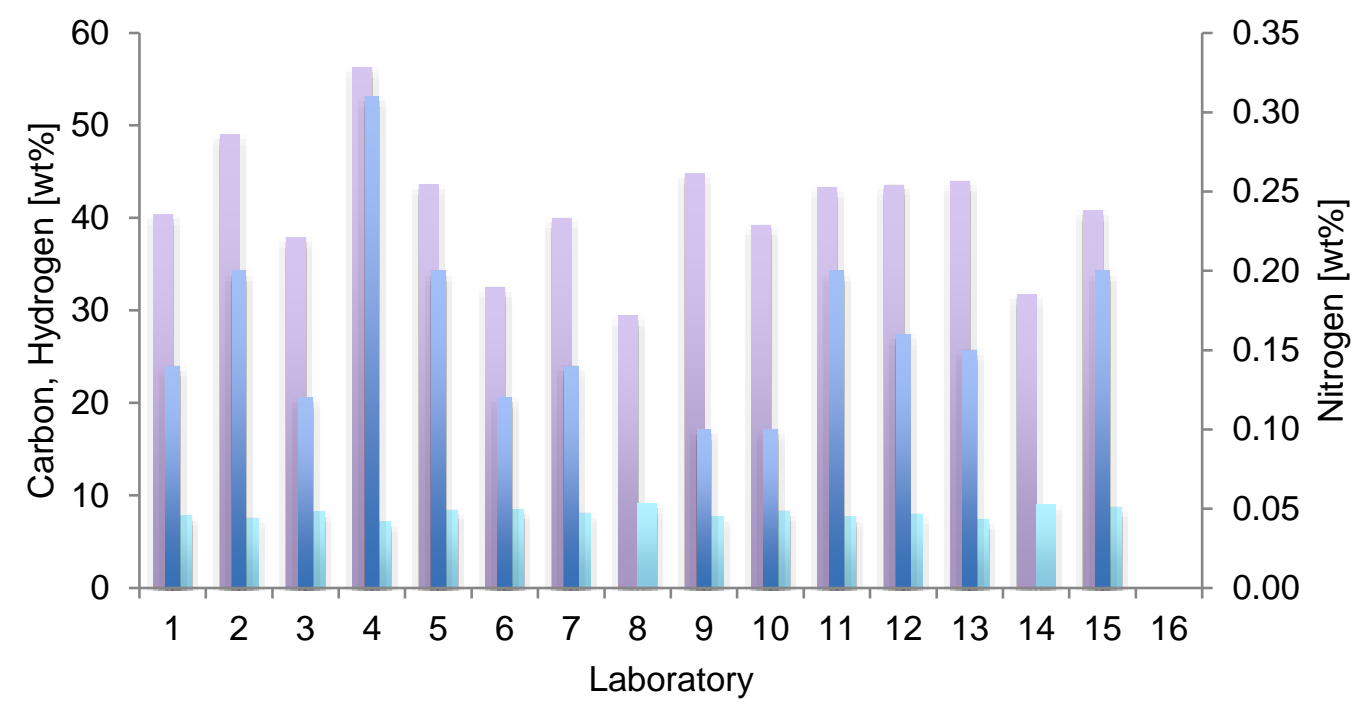

Figure 10. Carbon, hydrogen and nitrogen content (on w.b.) of poplar bio-oils

\section{Solids content and ash composition}

The solids content of poplar and blend oils is presented in Figure 11.

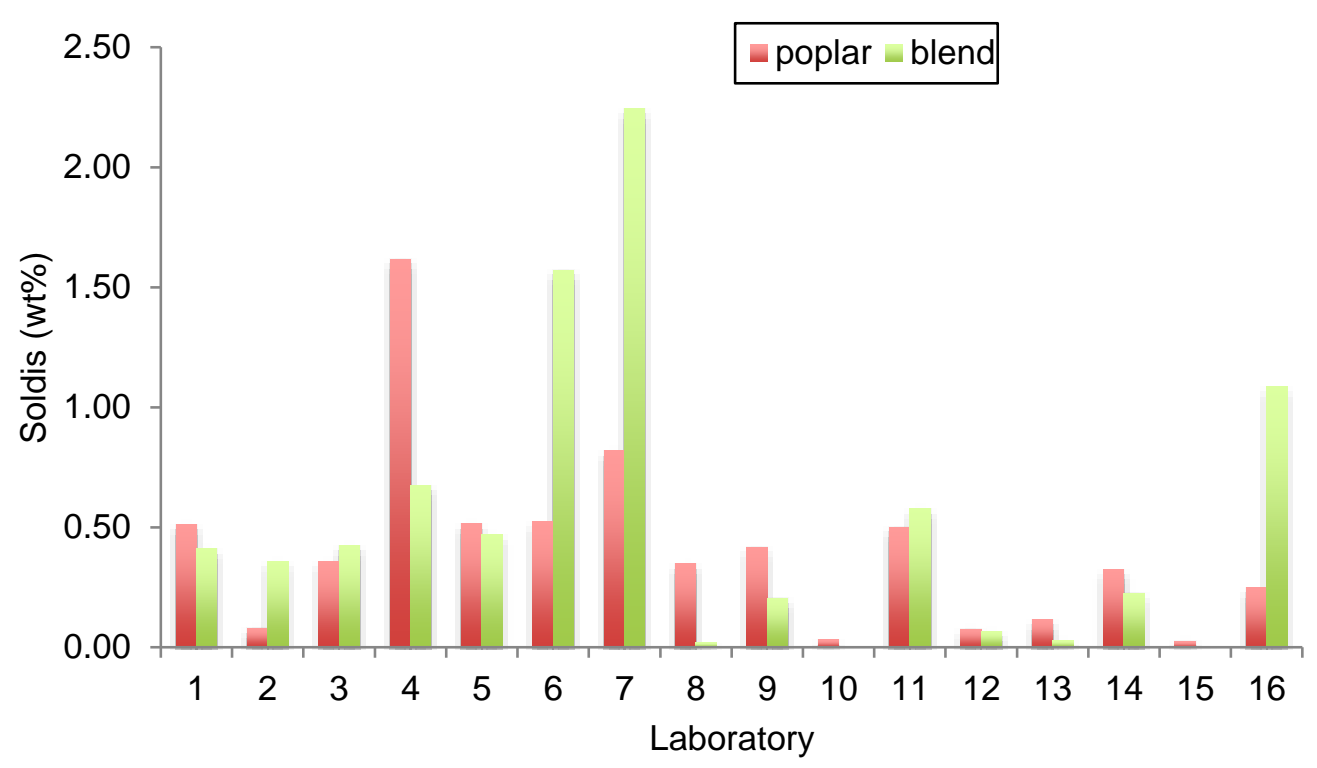

Figure 11 Distribution of solids in bio-oils from poplar and blend

The solids content in the bio-oils exhibits also an enormous range from 0.03 to 1.62 for poplar oil and from 0.02 to 2.24 for oils from the blended feedstock. The solids and ash loading in the bio-oil products is again drastically reduced by the use of the hot vapor filter (\#2, \#10, \#12). 


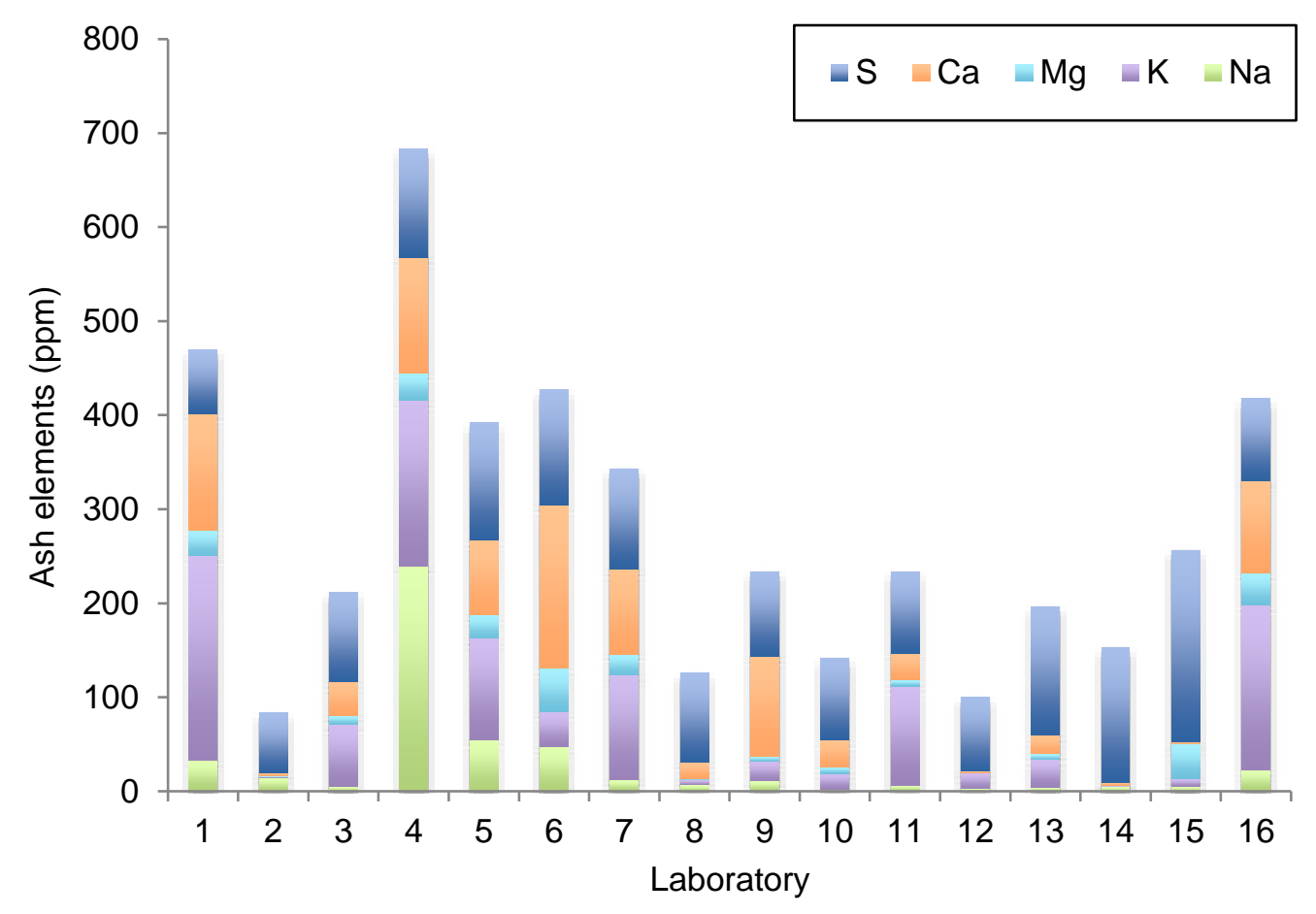

Figure 12. Ash composition (w.b.) of poplar bio-oil

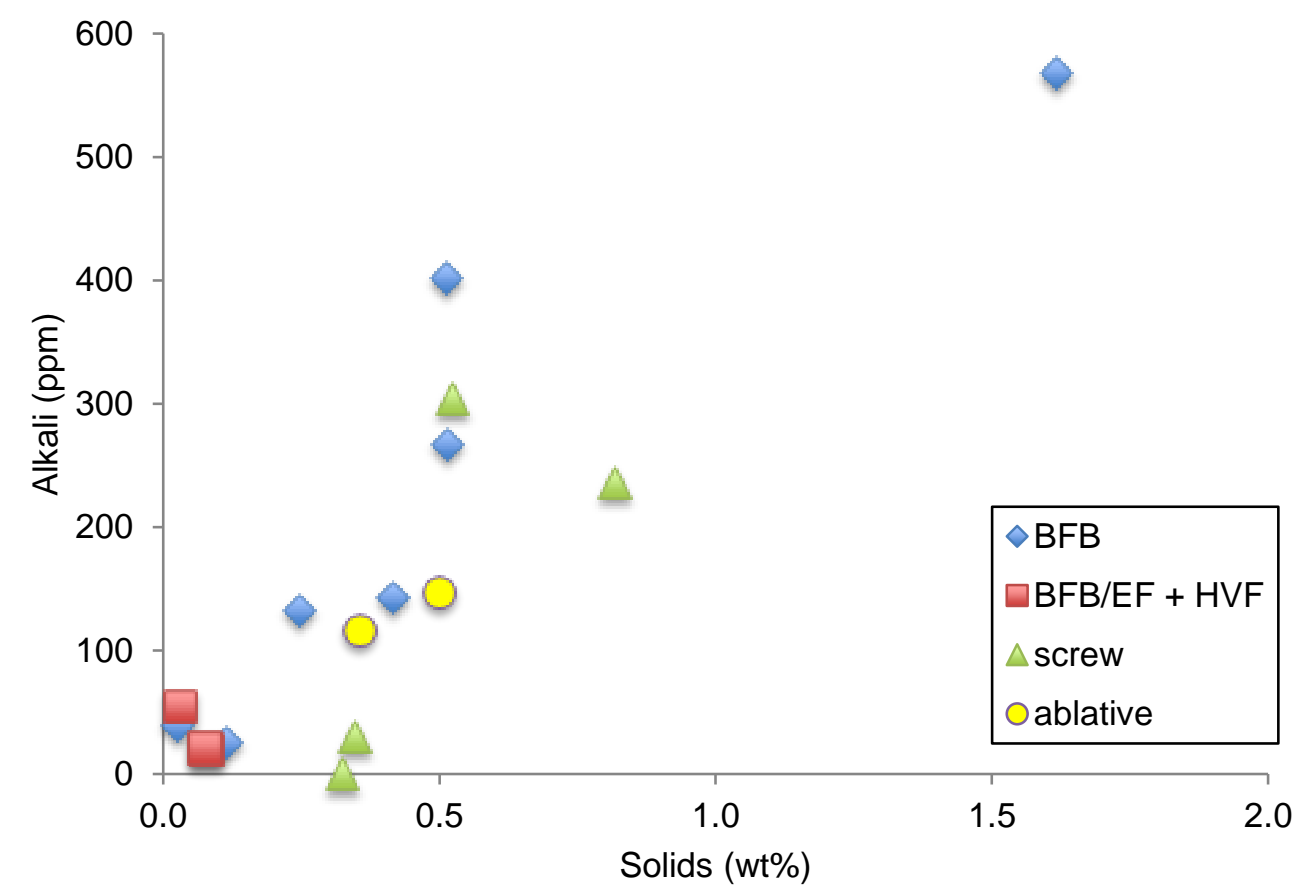

Figure 13. Correlation of solid and alkali content (w.b.) vs. technology

Note that the systems equipped with a hot vapor filter produced bio-oils with significantly reduced alkali metal and alkaline earth contamination (Figure 13). Also the BFB reactors have the tendency to exhibit a higher amount of solids composed of alkali metals. 


\section{Pyrolytic lignin}

Apart from water and water-soluble components fast pyrolysis bio-oils also contain a waterinsoluble fraction (pyrolytic lignin, PL) that can be precipitated as a fine brown powder. It is derived from lignin as the product of rearrangements of monomeric and oligomeric phenolics. Further it is discussed in the literature that it might be produced through thermal ejection of lignin oligomers in the presence of the hot reactor. ${ }^{14,28-31}$ The PL distribution is shown in Figure 14. The content varies from 3 to $29 \mathrm{wt} \%$ on wet basis (6 to $32 \mathrm{wt} \%$ on dry basis.

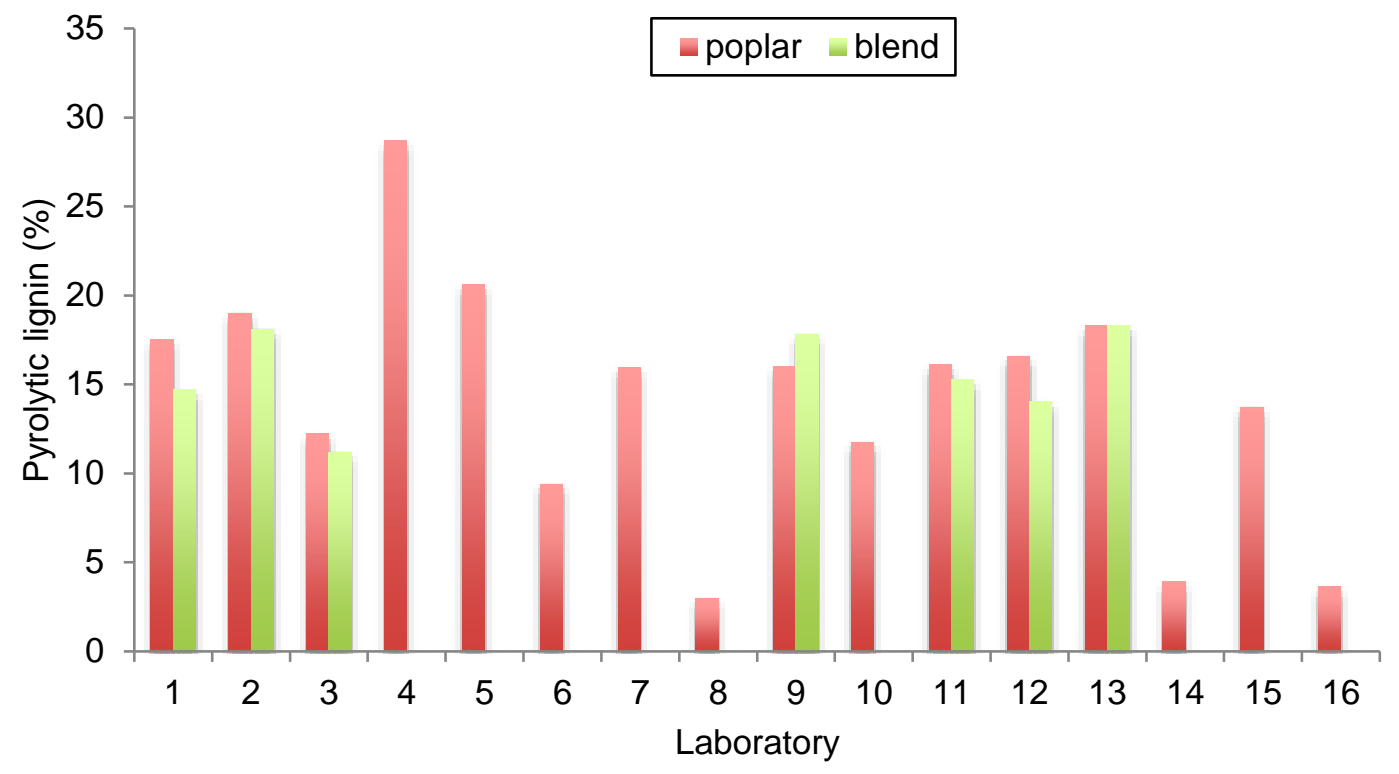

Figure 14. Content of pyrolytic lignin (wt\% on w.b.) in bio-oils from poplar and blend

As pyrolytic lignin corresponds to the water-insoluble part of bio-oil, consequently, oils with a larger water content should contain a smaller amount of water insolubles. Figure 15 illustrates the negative correlation between the water content and pyrolytic lignin content PL with a coefficient of determination of 0.89 .

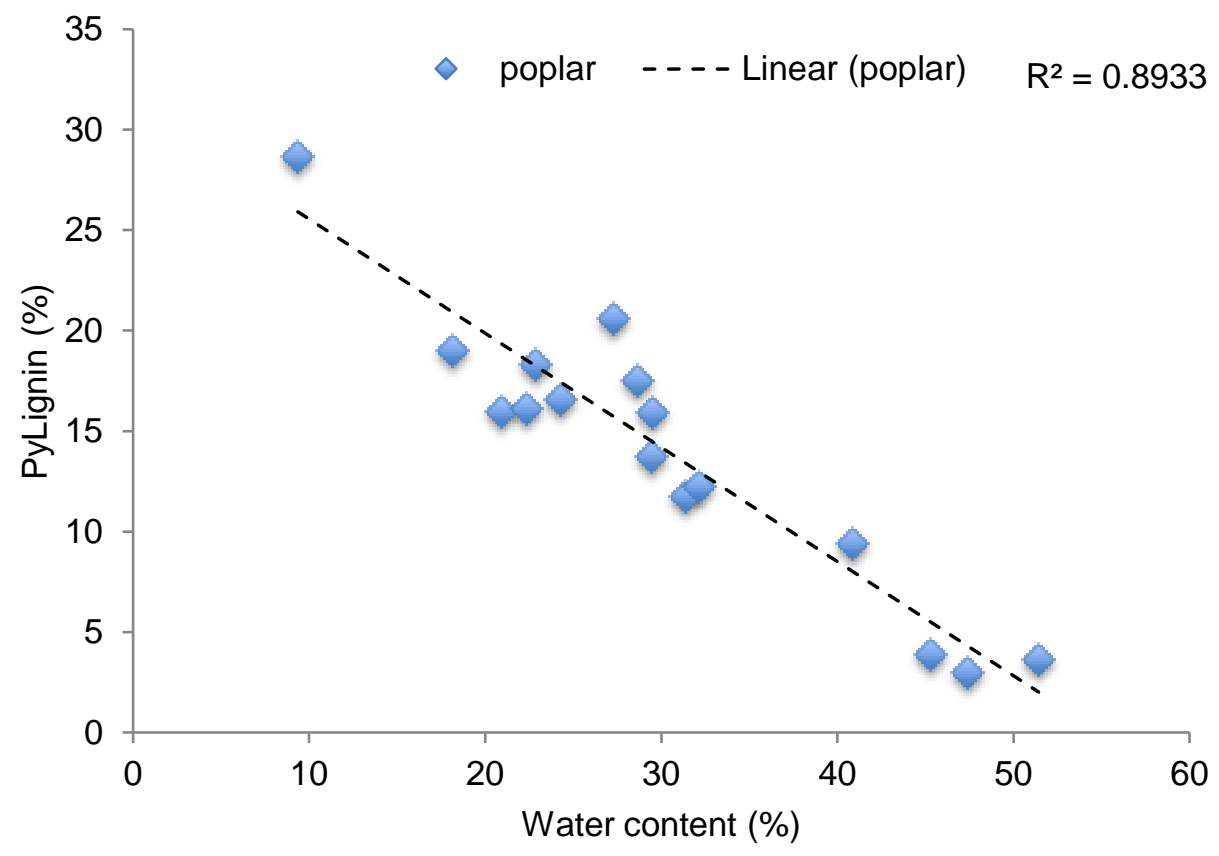


Figure 15. Correlation between water content and pyrolytic lignin content (w.b.) of poplar bio-oils

Another relationship is that between the viscosity of the bio-oil and the amount of pyrolytic lignin. As pyrolytic lignin resembles the higher molecular weight portion in bio-oils its content is positively correlated with the viscosity, as depicted in Figure 16 for poplar oil with a coefficient of determination of 0.901 .

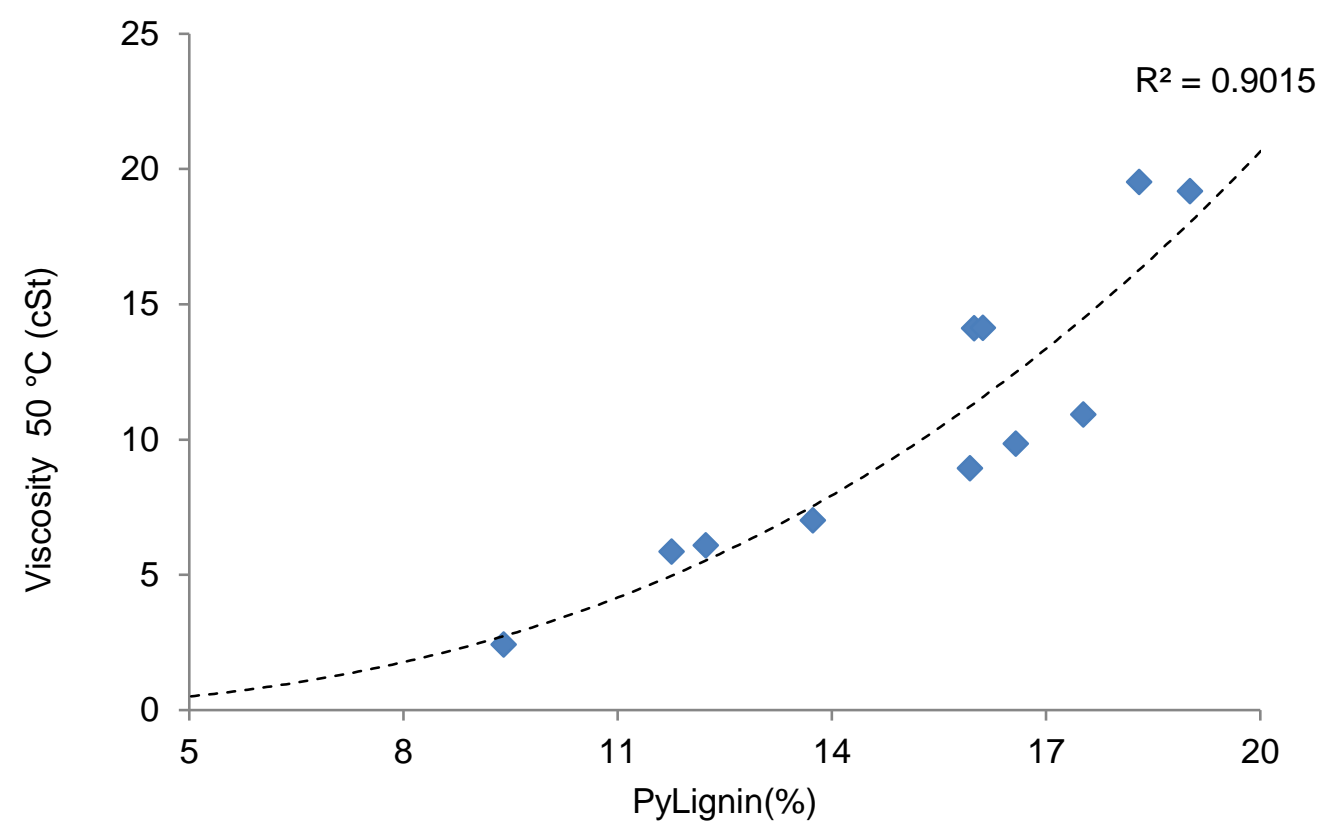

Figure 16. Poplar oil viscosity measured at $50{ }^{\circ} \mathrm{C}$ as a function of pyrolytic lignin content (wt $\%$ w.b.)

\section{Molecular weight Py-lignin (PL)}

Figure 17 shows no obvious correlation between the PL content and its average weight molecular weight data. It seems that the processes with hot vapor filtration do not crack lignin fragments in the filter, as their values are in the center of all BFB data. 


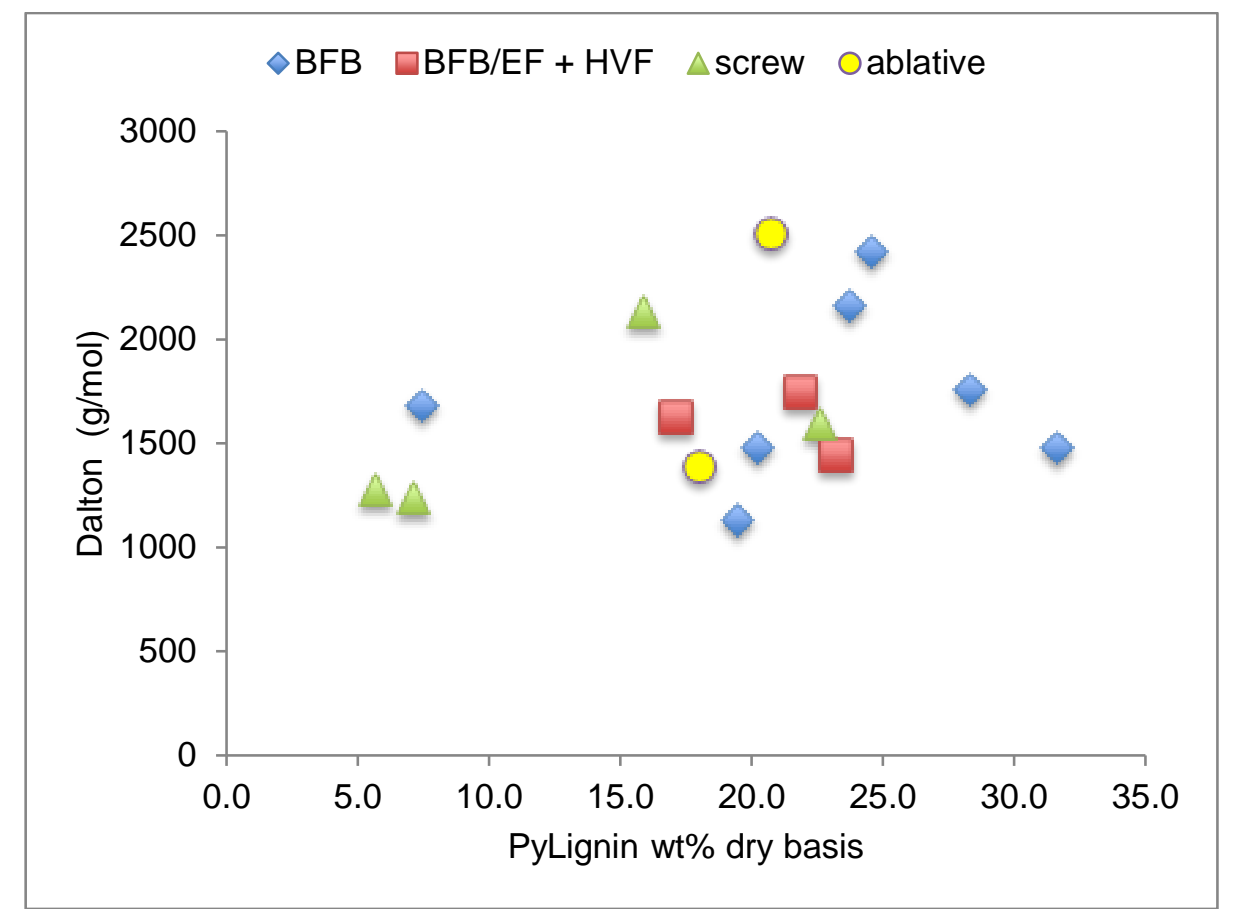

Figure 17. Correlation between PL content and average weight molecular weight

An interesting positive linear correlation is observed between the GPC data from whole biooil vs. the PL fraction (Figure 18). This is an interesting result as tedious PL precipitation would be unnecessary to calculate the mean molecular weight of a PL based on GPC data of the whole oil, as this is much simpler to obtain, just by injecting the bio-oil sample (after filtration) into the GPC system.

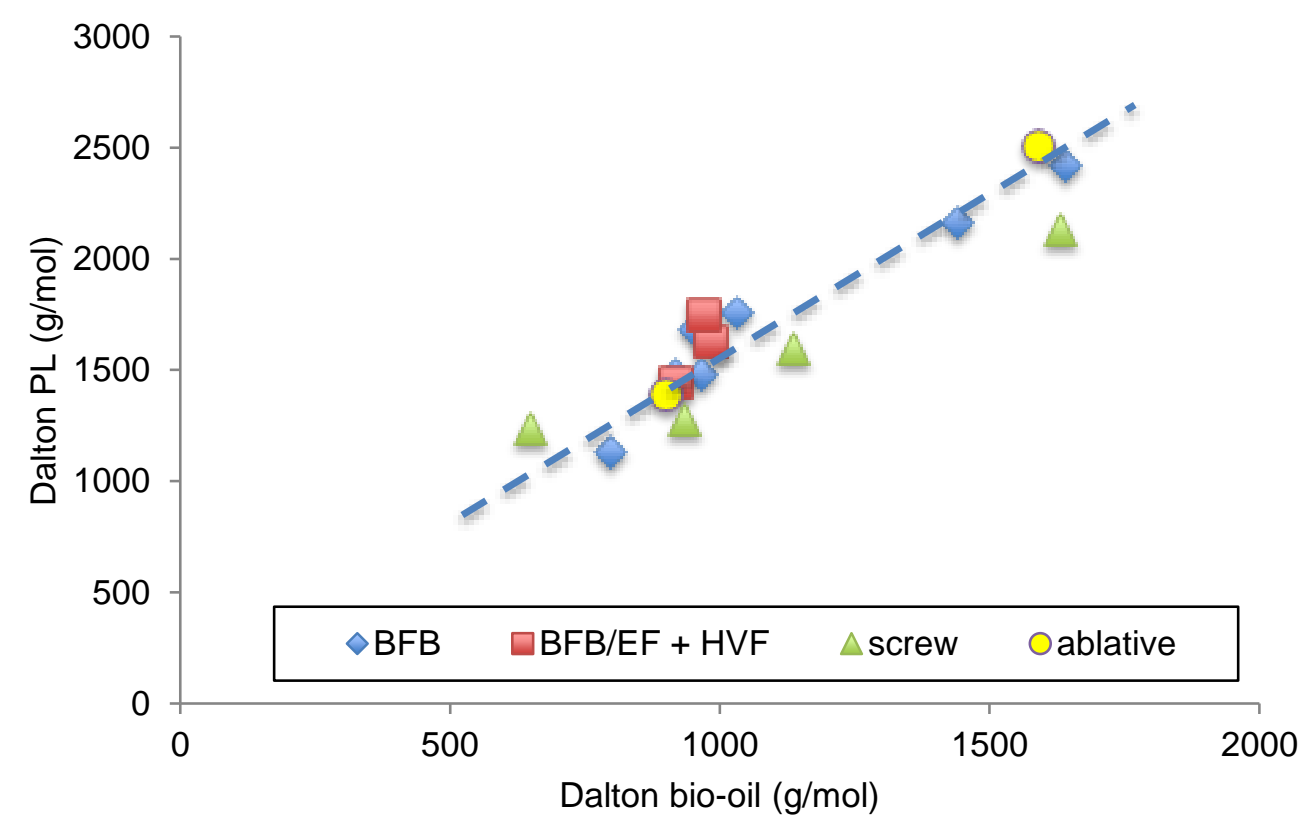

Figure 18. Correlation between the average weight molecular weights of bio-oils vs. PL, coeff. of determination 0.88 


\section{GC/MS}

GC/MS data were generated from all poplar oil samples. Comparison of the nonaromatic vs. aromatic portion showed a negative linear correlation with a coefficient of 0.91 (Figure 19). This correlation is valid for all pyrolysis systems.

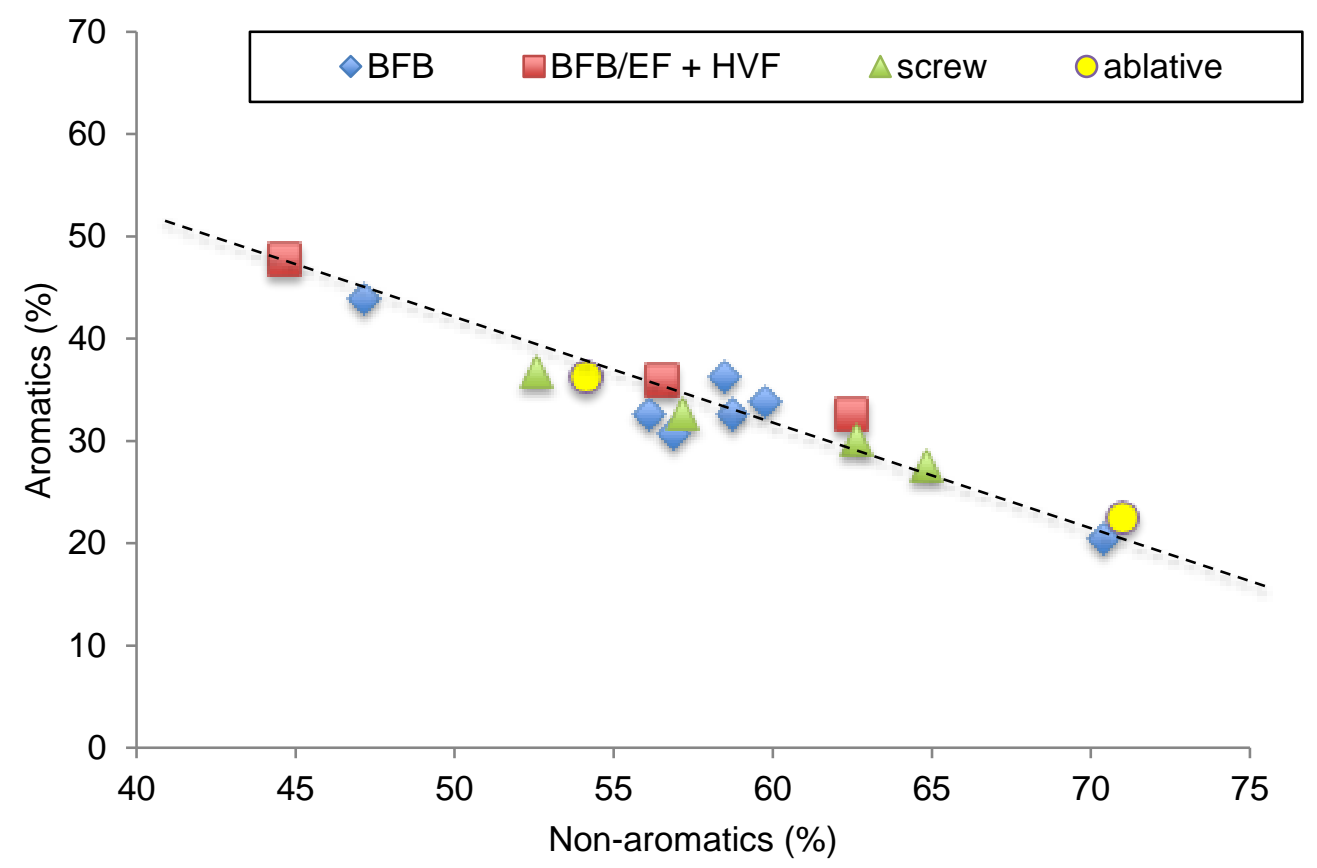

Figure 19. Correlation of nonaromatic fraction vs. aromatic fraction compared with the Analytical Pyrolysis-GC/MS pyrolysis technologies

Analytical pyrolysis with GC detection was performed from all feedstocks in order to find correlations between the analytical approach and technical pyrolysis. As can be seen from Figure 20 yields determined with analytical pyrolysis (large marks) give a good indication about the composition of bio-oils. The graph combines the overall results of all pyrolysis systems. Hence, analytical pyrolysis would be a useful tool to predict bio-oil composition. Calculation basis was on area \% after normalization to $100 \mu \mathrm{g}$ sample weight. 


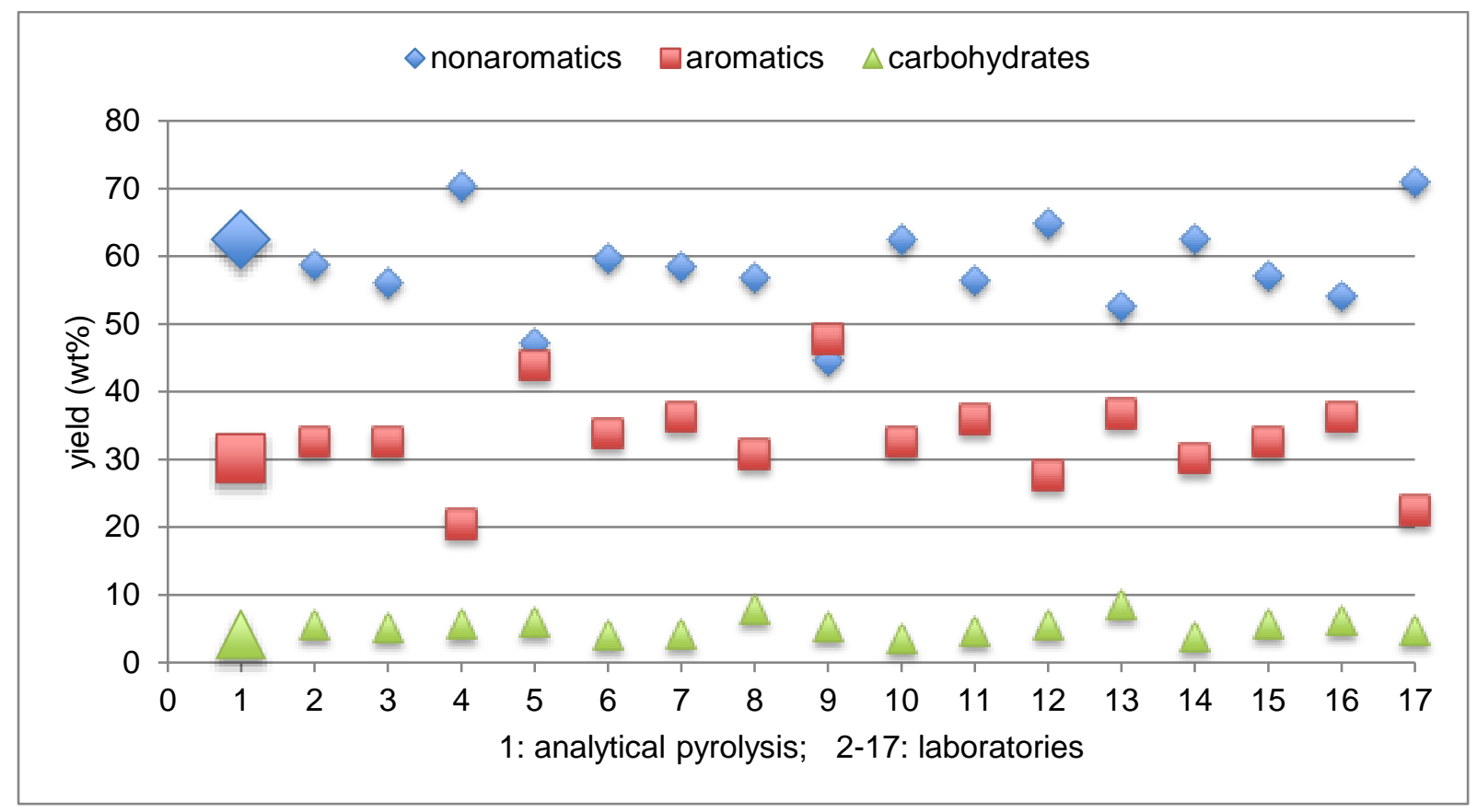

Figure 20. Yields of main chemical groups as obtained from analytical pyrolysis (large marks) and obtained in BFB bio-oils from poplar

\section{Mass balance}

An attempt was made to establish a mass balance making use of all quantitative results from poplar oils. Figure 21 summarizes the results and illustrates that the undetermined portion varies between 9.5 and $28.5 \mathrm{wt} \%$. The undetermined portion could be assigned mainly to higher molecular weight sugars and other water soluble components which were not detected with the methods used in this round robin testing.

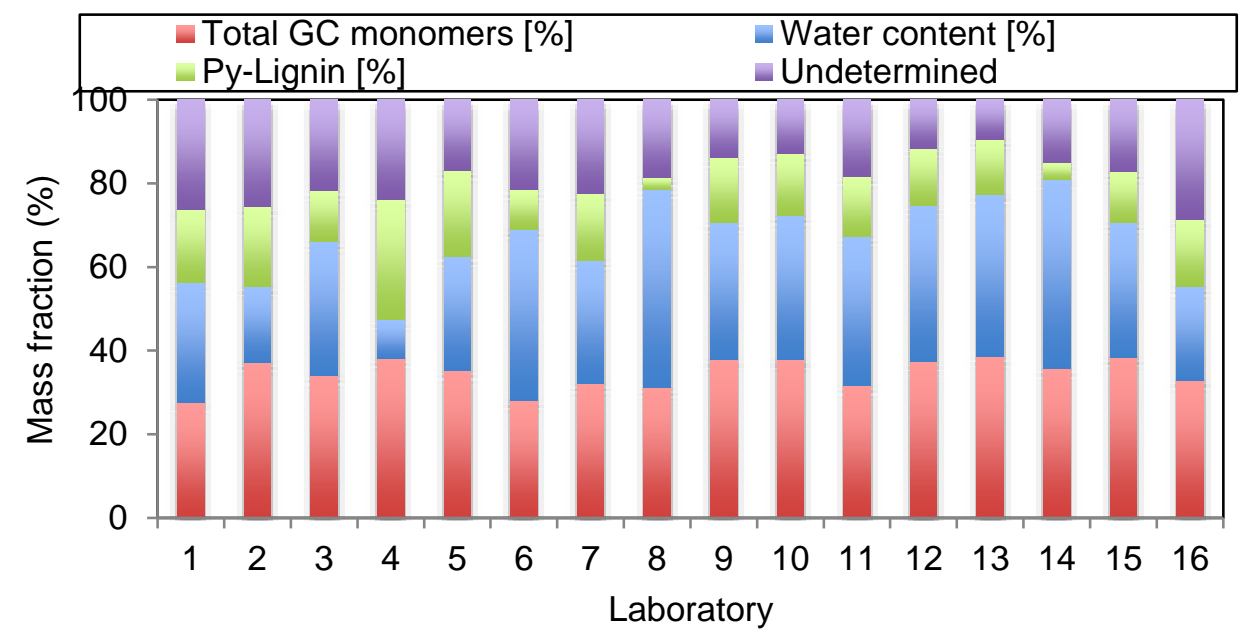

\section{CONCLUSIONS}

Figure 21. Mass balance of poplar oils from all participants

It is clear that all laboratory reactor systems for bio-oil production do not produce equivalent products. The mechanism of heat transfer used can impact the bio-oil composition through the time-temperature relationship. Also, the measurement of reaction temperature might be inaccurate. In addition, the product collection method can impact the product composition through either filtering out solid byproducts or through vapor separation as a result of collection of the liquid product at different temperatures. 
The huge data pool and the fact that all samples were analyzed by only one laboratory made it possible to determine correlations:

- the aromatics and non-aromatics in bio-oil correlate as detected by GC/MS,

- the mean molecular weight of the bio-oils correlates with those from pyrolytic lignin.

- viscosity correlates with pyrolytic lignin content

- water content correlates with pyrolytic lignin content

- viscosity correlates with water content

Four parameters were able to discriminate the four technologies applied (bubbling bed, bubbling bed \& entrained flow with hot vapor filtration, screw reactors, and ablative reactors). Water, solids, viscosity, and total acid number were related to the applied technology. Most negative results were obtained from auger (screw) reactors, whereas bubbling fluidized beds with hot vapor filtration showed the most positive bio-oil characteristics, mainly in terms of solids and ash content.

Another interesting observation was that none of the laboratories was able to produce a single phase bio-oil from wheat straw, they were all phase separated into an aqueous and a heavy tarry phase. This was due to high ash content of the straw decreasing oil yield and enhancing reactions causing water formation. The phase separation of the pyrolysis liquids from the blend was less pronounced. All bio-oils from hybrid poplar arrived as a single phase liquid and could be analyzed completely.

Overall, the use of round robins is useful both for providing insights on differences between performance of laboratory and bench-scale pyrolysis units and helps the participants by allowing comparison of results with other laboratories. It must be pointed out that fast pyrolysis bio-oils are completely different from mineral oils or biodiesels. Special care has to be used in the proper handling and sampling of these bio-oils in order to ensure the homogeneity of the bio-oil.

\section{ACKNOWLEDGEMENTS}

The feedstocks preparation team at INL (Garold Gresham, Marnie Cortez, Tyler Westover, Neal Yancey, Kevin Kenney and Richard Hess) is acknowledged for their effort. All of the participating laboratories are acknowledged for their operation of their processing systems and preparation of bio-oil samples. The analytical team at Thünen Institute (Dietrich Meier, Anna-Lena Schleuß, Alina Forner, Silke Radtke, Ariane Hartmann, Patrick Eidam, Christian Geyer, and Ingrid Fortmann) is also gratefully acknowledged for their effort. Finally, all the funding agencies for the laboratories are also acknowledged. 


\section{REFERENCES}

(1) IEA http://www.pyne.co.uk/? id=18 (accessed Dec. 13, 2016).

(2) Oasmaa, A.; Elliott, D. C.; Müller, S., Quality control in fast pyrolysis bio-oil production and use. Environmental Progress \& Sustainable Energy 2009, 28 (3), 404-409.

(3) Oasmaa, A.; van de Beld, B.; Saari, P.; Elliott, D. C.; Solantausta, Y., Norms, standards, and legislation for fast pyrolysis bio-oils from lignocellulosic biomass. Energy Fuels 2015, 29 (4), 2471-2484.

(4) Elliott, D. C. Analysis and upgrading of biomass liquefaction products; Pacific Northwest Laboratory: Richland, Washington, USA, 1983.

(5) Oasmaa, A.; Leppämäki, E.; Koponen, P.; J. and Tapola, E. L., Physical characterisation of biomass-based pyrolysis liquids: Application of standard fuel oil analyses. VTT: Espoo, Finland, 1997; Vol. 306, p 87.

(6) Oasmaa, A.; Peacocke, C., A guide to physical property characterisation of biomass-derived fast pyrolysis liquids. Espoo, 2001; p 65.

(7) Oasmaa, A. Fuel oil quality properties of wood-based pyrolysis liquids. Dissertation, University of Jyväskylä, 2003.

(8) Oasmaa, A.; Peacocke, C., Properties and fuel use of biomass derived fast pyrolysis liquids - A guide. VTT: Espoo, 2010; p $79+$ app. 46 p.

(9) McKinley, J. W.; Overend, R. P.; Elliott, D. C. In The ultimate analysis of biomass liquefaction products: the results of the IEA round robin \#1, Proceedings of Specialists Workshop on Biomass Pyrolysis Oil Properties and Combustion, Estes Park, CO, USA, Sept. 26-28; NREL, Ed. NREL paper CP-430-7215: Estes Park, CO, USA, 1994; pp 34-53.

(10) Meier, D., New methods for chemical and physical characterization and round robin testing. In Fast Pyrolysis of Biomass: A Handbook, CPL Ltd., Newbury, UK, Czernik, S.; Diebold, J.; Meier, D.; Oasmaa, A.; Peacocke, C.; Piskorz, J.; Radlein, D.; Bridgwater, A. V., Eds. 1999; pp 92-101.

(11) Oasmaa, A.; Meier, D., Norms and standards for fast pyrolysis liquids. 1. Round robin test. J. Anal. Appl. Pyrolysis 2005, 73, 323-334.

(12) Elliott, D. C.; Oasmaa, A.; Preto, F.; Meier, D.; Bridgwater, A. V., Results of the IEA round robin on viscosity and stability of fast pyrolysis bio-oils. Energy Fuels 2012, 26, 3769-3776.

(13) Elliott, D. C.; Oasmaa, A.; Meier, D.; Preto, F.; Bridgwater, A. V., Results of the IEA round robin on viscosity and aging of fast pyrolysis bio-oils: Long-term tests and repeatability. Energy Fuels 2012, 26 (12), 7362-7366.

(14) Scholze, B.; Meier, D., Characterization of the water-insoluble fraction from fast pyrolysis liquids (pyrolytic lignin). Part I. Py-GC/MS, FTIR, and functional groups. J. Anal. Appl. Pyrolysis 2001, 60, 41-54.

(15) Oasmaa, A.; Sundqvist, T.; Kuoppala, E.; García-Perez, M.; Solantausta, Y.; Lindfors, C.; Paasikallio, V., Controlling the phase stability of biomass fast pyrolysis bio-oils. Energy Fuels 2015, 29 (7), 4373-4381.

(16) Oasmaa, A.; Solantausta, Y.; Arpiainen, V.; Kuoppala, E.; Sipila, K., Fast pyrolysis bio-oils from wood and agricultural residues. Energy Fuels 2010, 24, 1380-1388.

(17) Venderbosch, R. H., A Critical View on Catalytic Pyrolysis of Biomass. ChemSusChem 2015, 8 (8), 1306-1316.

(18) Paasikallio, V.; Lindfors, C.; Kuoppala, E.; Solantausta, Y.; Oasmaa, A.; Lehto, J.; Lehtonen, J., Product quality and catalyst deactivation in a four day catalytic fast pyrolysis production run. Green Chem. 2014, 16 (7), 3549-3559. 
(19) Lehto, J.; Oasmaa, A.; Solantausta, Y.; Kyto, M.; Chiaramonti, D. Fuel oil quality and combustion of fast pyrolysis bio-oils; 87; VTT Technical Research Centre of Finland: Espoo, Finland, 2013; p 79.

(20) Oasmaa, A.; Källi, A.; Lindfors, C.; Elliott, D. C.; Springer, D.; Peacocke, C.; Chiaramonti, D., Guidelines for transportation, handling, and use of fast pyrolysis bio-oil. 1. Flammability and toxicity. Energy Fuels 2012, 26 (6), 3864-3873.

(21) Oasmaa, A.; Kuoppala, E.; Selin, J.-F.; Gust, S.; Solantausta, Y., Fast Pyrolysis of Forestry Residue and Pine. 4. Improvement of the Product Quality by Solvent Addition. Energy Fuels 2004, 18 (5), 1578-1583.

(22) Czernik, S.; Bridgwater, A. V., Overview of applications of biomass fast pyrolysis oil. Energy Fuels 2004, 18 (2), 590-598.

(23) Johansson, A. C.; Wiinikka, H.; Sandstrom, L.; Marklund, M.; Ohrman, O. G. W.; Narvesjo, J., Characterization of pyrolysis products produced from different Nordic biomass types in a cyclone pilot plant. Fuel Process. Technol. 2016, 146, 9-19.

(24) Sundqvist, T.; Oasmaa, A.; Koskinen, A., Upgrading Fast Pyrolysis Bio-Oil Quality by Esterification and Azeotropic Water Removal. Energy Fuels 2015, 29 (4), 25272534.

(25) French, R. J.; Stunkel, J.; Black, S.; Myers, M.; Yung, M. M.; Iisa, K., Evaluate Impact of Catalyst Type on Oil Yield and Hydrogen Consumption from Mild Hydrotreating. Energy Fuels 2014, 28 (5), 3086-3095.

(26) Capunitan, J. A.; Capareda, S. C., Characterization and separation of corn stover bio-oil by fractional distillation. Fuel 2013, 112, 60-73.

(27) Ferrell, J. R., III; Olarte, M. V.; Christensen, E. D.; Padmaperuma, A. B.; Connatser, R. M.; Stankovikj, F.; Meier, D.; Paasikallio, V., Standardization of chemical analytical techniques for pyrolysis bio-oil: history, challenges, and current status of methods. Biofpr 2016.

(28) Scholze, B.; Hanser, C.; Meier, D., Characterization of the water-insoluble fraction from fast pyrolysis liquids (pyrolytic lignin). Part II. GPC, carbonyl groups, and 13CNMR. J. Anal. Appl. Pyrolysis 2001, 58-59, 387-400.

(29) Bayerbach, R.; Nguyen, V. D.; Schurr, U.; Meier, D., Characterization of the water-insoluble fraction from fast pyrolysis liquids (pyrolytic lignin) Part III. Molar mass characteristics by SEC, MALDI-TOF-MS, LDI-TOF-MS, and Py-FIMS. J. Anal. Appl. Pyrolysis 2006, 77, 95-101.

(30) Bayerbach, R.; Meier, D., Characterization of the water-insoluble fraction from fast pyrolysis liquids (pyrolytic lignin) Part IV. Structure elucidation of oligomeric molecules J. Anal. Appl. Pyrolysis 2008, 85, 98-107.

(31) Fratini, E.; Bonini, M.; Oasmaa, A.; Solantausta, Y.; Teixeira, J.; Baglioni, P., SANS analysis of the microstructural evolution during the aging of pyrolysis oils from biomass. Langmuir 2006, 22 (1), 306-312. 